\title{
Study of Shell-Mold Thermal Resistance: Laboratory Measurements, Estimation from Compact Strip Production Plant Data, and Observation of Simulated Flux-Mold Interface
}

\author{
J. MANUEL GONZÁLEZ DE LA C., TANIA M. FLORES F., \\ and A. HUMBERTO CASTILLEJOS E.
}

\begin{abstract}
The slag film that forms between the shell and mold in steel continuous casting is key in regulating the heat transfer between them. Generally, the mechanisms proposed are related to the phenomena associated with the formation of crystals in the solid layer of the film, such as the appearance of internal pores and surface roughness, which decrease phononic conduction through the layer and interfacial gap with the mold, respectively, and the emergence of crystals themselves, which reduce the transmissivity of infrared radiation across the layer. Due to the importance of the solid layer, this study investigates experimentally the effective thermal resistance, $R_{\mathrm{T}}$, between a hot Inconel surface and a cold $\mathrm{Cu}$ surface separated by an initially glassy slag disk, made from powders for casting low and medium-carbon steels, denoted as A and $\mathrm{B}$, respectively. In the tests, an initially mirror-polished disk is sandwiched for 10,800 seconds while the Inconel temperature, away from the disk face, is maintained steady at a value, $T_{\mathrm{c}}$, between $973 \mathrm{~K}$ and $1423 \mathrm{~K}\left(700^{\circ} \mathrm{C}\right.$ and $\left.1150{ }^{\circ} \mathrm{C}\right)$-below the liquidus temperature of the slags. The disks have a thickness, $d_{\mathrm{t}}$, between $\sim 0.7$ and $3.2 \mathrm{~mm}$. Over the range of conditions studied, mold slag B shows $R_{\mathrm{T}} 33$ pet larger than slag $\mathrm{A}$, and microscopic observation of disks hints that the greater resistance arises from the larger porosity developed in B. This finding is supported by high-temperature confocal laser scanning microscope observations of the evolution of the surface of slag parallelepipeds encased between Pt sheets, which reveal that during devitrification the film surface moves outward not inward, contrary with what is widely claimed. This behavior would favor contact of the slag with the mold for both kinds of powders. However, in the case of slag A, the crystalline grains growing at or near the surface pack closely together, leaving only few and small empty spaces. In slag B, crystalline grains pack loosely and many and large empty spaces arise in and below the surface. Estimation from plant data shows $R_{\mathrm{T}}$ values smaller than measured ones, suggesting that the process film slag thickness must be considerably thinner than those of laboratory disks. However, the difference in thermal resistance of both powders, averaged over the mold length, is close to the dissimilarity found in laboratory.
\end{abstract}

DOI: $10.1007 / \mathrm{s} 11663-016-0704-\mathrm{Z}$

(C) The Minerals, Metals \& Materials Society and ASM International 2016

\section{INTRODUCTION}

THE mold is the most critical component of the steel continuous casting machine; the rate and uniformity of heat removal from the strand, especially near the meniscus, controls the surface quality of the product, as well as the productivity and safety of the process. An excessive or uneven rate of heat extraction from the

J. MANUEL GONZÁLEZ DE LA C., Doctoral Candidate, TANIA M. FLORES F., M.Sc. Graduate, and A. HUMBERTO CASTILlEJOS E., Professor, are with the Laboratory of Process Metallurgy, Department of Metallurgical Engineering, Centro de Investigación y de Estudios Avanzados, CINVESTAV Unidad Saltillo, Av. Industria Metalúrgica 1062, Parque Industrial SaltilloRamos Arizpe, 25900, Ramos Arizpe, Coahuila, Mexico. Contact email: humberto.castillejos@cinvestav.edu.mx

Manuscript submitted January 7, 2016

Article published online June 13, 2016. newly solidified shell may induce thermal stresses, which ultimately might cause longitudinal cracks. ${ }^{[1]}$ On the other hand, insufficient heat removal may lead to relatively frail spots in the shell that could culminate in breakouts. ${ }^{[2]}$ Rejection or reconditioning of cracked slabs causes considerable economic losses, ${ }^{[3]}$ and slab breakouts are major upsets, which bring about safety hazards, machine damage, and line stoppages. ${ }^{[4]}$ Thus, heat transfer from the shell to the mold must match the operating conditions, e.g., steel composition, casting speed, and mold design, by choosing the mold powder that has adequate crystallization tendency, solidification temperature, and effective (phononic plus photonic) thermal conductivity, and that produces a slag film and solid slag layer-mold gap with the right thicknesses.

The slag film is made of a liquid layer beside the shell and a solid layer next to the $\mathrm{Cu}$ mold. The latter generally has both glassy and crystalline phases 
accommodated in complex fashion. ${ }^{[5,6]}$ Through the liquid and solid layers, heat is transferred by conduction and radiation and reaches the mold by conduction through an air gap that is claimed to form between the solid layer and the mold. ${ }^{[7-9]}$ Normally, it is stated that the gap arises because the crystalline phase has a higher density than the glass, and therefore crystallization results in shrinkage of the solid flux layer. ${ }^{[10,11]}$ In an investigation carried out to determine the surface roughness of solidified mold fluxes, it was found that this was in the range of 10 to $30 \mu \mathrm{m}$, when the crystalline phase precipitated; ${ }^{[12]}$ this surface roughness was claimed to agree with the calculated thickness of the air gap assumed to form between the mold and the solidified slag layer. Furthermore, it was disclosed that the surface roughness of mold powder slags for casting medium-carbon steels is larger than that of mold slags used for low-carbon steels. ${ }^{[12]}$ Other authors indicated that substantial shrinkage occurs in mold fluxes for medium-carbon steels due to larger volumetric ratio and faster growth rate of cuspidine, as compared to what occurs in mold fluxes for low-carbon steels; ${ }^{[13]}$ however, no clear evidence of the shrinkage was provided.

For studying heat transfer, different methods were devised and, according to their experimental principles, were classified into three categories: (1) sandwiching a mold slag layer between hot and cold solid walls, ${ }^{[7,14-17]}$ (2) dipping a cold finger into molten slag ${ }^{[8,9,18,19]}$ or into a bath of molten slag and steel, ${ }^{[20,21]}$ and (3) exposing a mold slag layer to infrared radiation. ${ }^{[22-25]}$

In the sandwiching methods, measures are taken to establish linear temperature gradients through the measuring system, which consists of hot body, mold flux film, and cold body. This requires that the heating source, simulating the strand, has sufficient power to balance the heat extracted by a water- or air-cooled body simulating the mold and that steady-state conditions are established. Heating methods involved direct resistance heating, ${ }^{[14]}$ electrical resistance cartridges, ${ }^{[15]}$ electromagnetic induction heating, ${ }^{[16,17]}$ and gas burners. ${ }^{[7]}$ These kinds of methods were used with slag film thicknesses between 0.5 and $3.0 \mathrm{~mm}$ and showed that the heat flux can vary considerably with slag composition. ${ }^{[14]}$ Also, an interfacial thermal resistance equivalent to an air gap of 20 to $50 \mu \mathrm{m}$ was estimated, and the radiative heat transfer was reported to amount to $20 \mathrm{pct}$ of the total heat flux, with crystallization inhibiting radiative heat transfer. ${ }^{[15]}$ The interfacial thermal resistance was found to increase with flux film thickness, and for the same thickness, the interfacial resistance was larger for fluxes used for medium-carbon steel than for fluxes dedicated to low-carbon steels; this behavior was attributed to greater crystallization of the first kind of powders. ${ }^{[16]}$ Furthermore, it was claimed that the structure of flux films obtained in experiments is similar to that displayed by films taken from the mold wall after continuous casting, but there is uncertainty since the total thickness of the films recovered from the mold after casting might be different from those existing during casting. ${ }^{[17]}$ In an experimental setup, which involved vertical walls and pouring of liquid slag in between the walls, the contact resistances at both interfaces were found to be significant, averaging $\sim 1.5 \times 10^{-3} \mathrm{~m}^{2} \mathrm{~K} / \mathrm{W}$, equivalent to an air gap of $\sim 100 \mu \mathrm{m} .{ }^{[7]}$ Overall (i.e., film plus interfacial), effective thermal resistances, between $0.7 \times 10^{-3}$ and $5.5 \times 10^{-3} \mathrm{~m}^{2} \mathrm{~K} / \mathrm{W}$, were reported for film thicknesses between 0.5 and $3.7 \mathrm{~mm} .^{[7,15-17]}$

Cold finger dipping methods deal with freezing a slag shell over a cold body that is immersed into a molten bath and with recording of temperatures, at certain locations, as a function of time. ${ }^{[8,9,18-21]}$ The temperature data obtained are converted to heat flux values by solving a one- ${ }^{[9,18,19]}$ or two-dimensional ${ }^{[20]}$ inverse heat conduction problem. In the earlier study, it was reported that for a given composition the effective thermal conductivity was a strong function of superheat and that at high temperatures the dominant heat-transfer mechanism is radiation conduction. ${ }^{[18]}$ In a recent study, where the finger was water cooled and instrumented with several thermocouples, it was reported that the interfacial thermal resistance accounted for $\sim 78$ pct of the total thermal resistance and amounted to $\sim 1.9 \times 10^{-3} \mathrm{~m}^{2} \mathrm{~K} / \mathrm{W} .^{[19]}$ In experiments where the finger included oscillation, the estimated interfacial thermal resistance reached slightly higher values, up to $\sim 2.25 \times 10^{-3} \mathrm{~m}^{2} \mathrm{~K} / \mathrm{W} .{ }^{[9]}$ Apparently, oscillation of the mold caused a rougher surface of the slag layer in contact with the copper finger. An experimental apparatus for simulating the initial solidification of a low-carbon steel produced a slag film, between the mold and the shell, with thickness in the range of 1.4 to 2.4 mm. ${ }^{[20]}$ Park et al. ${ }^{[21]}$ used an oscillating mold simulator and found, for a certain mold slag, that the flux film forming between the solidified steel strip and the water-cooled mold passed from being fully glassy close to the top of the mold to increasingly crystalized at lower positions. The authors mentioned that the local state of crystallization varied with mold flux, even among fluxes dedicated to casting the same steel grade. Therefore, quantitative characterization methods are needed to compare the crystallization and heat-transfer behavior of lots of the same powders or of different powders intended for casting the same or different steel grades.

Several investigations involving exposure of a slag disk to infrared radiation were developed to determine the radiative heat flux through molten and solid layers of slags used for casting different kinds of steels. ${ }^{[22-25]}$ It was reported that the optical properties among various mold fluxes, for low- and medium-carbon steels, are similar and that the larger radiative heat flux passing through low-carbon steel slags is due to the increase in thickness ratio of molten to crystalline layer. ${ }^{[2]}$ The authors reported that in the molten layer the ratio of radiative to total heat flux amounts to around 40 pct and that in the crystalline layer this ratio is just 7 pct when the total thickness of the flux film is $1.5 \mathrm{~mm} .{ }^{[22]} \mathrm{In}$ another study, where the slag disk was on top of a water-cooled $\mathrm{Cu}$ finger, it was reported that full crystallization of the slag disk reduced the heat-transfer rate by 20 pct compared with a completely glassy disk. ${ }^{[23]}$ The reflectivity caused by scattering of radiation at crystal grain boundaries was pointed out as an efficient 
factor for reducing radiation heat transfer, and thus it was indicated that the heat transfer across the mold flux film is primarily dominated by thermal conduction. ${ }^{[26]}$

Most of the studies regarding the influence of mold powders on heat transfer in the continuous casting mold were concerned with conventional slab casting. However, in thin slab casting, the choice of powder becomes more critical because casting speeds are much higher, and thus the small slag consumption leads to very thin liquid and solid slag layers. For a slab section size of $50 \times 1300 \mathrm{~mm}^{2}$ and a casting speed of $5.5 \mathrm{~m} / \mathrm{min}$, a consumption of $0.07 \mathrm{~kg} / \mathrm{m}^{2}$ was measured. ${ }^{[27]}$ This consumption would give an estimated average liquid film thickness of $\sim 27 \mu \mathrm{m}$ and possibly a solid layer of $\sim 270 \mu \mathrm{m}$. This value is in line with films of 200 and $300 \mu \mathrm{m}$ that were collected in a thin slab casting mold. ${ }^{[2]}$ The authors reported that the amorphous layer appearing in the films, at the strand side, was formed possibly from the liquid phase, immediately after casting. ${ }^{[28,29]}$ Thinner films, ranging between 120 and $205 \mu \mathrm{m}$, were reported by other authors. ${ }^{[30]}$ Also, it was disclosed that the surface roughness of slag films collected from a thin slab casting mold was small, only $2 \mu \mathrm{m}$ for the surface on the mold side and none over the strand side surface. ${ }^{[29]}$ Thus, the authors indicated that the interfacial thermal resistance is not as important as is widely assumed and that heat transfer during thin slab casting is mainly controlled by the slag film properties and characteristics. ${ }^{[29]}$ The minor role of the interfacial thermal resistance during casting in actual molds was supported by observing that the film is subjected to static pressure from the molten steel, which acts to slim the interfacial gap. ${ }^{[31]}$ A recent study intended to correlate the mold heat flux with casting conditions used in compact strip production (CSP) slab casters introduced the mold powder influence through their viscosity and break-point temperature. ${ }^{[32]}$ The correlation revealed a decrease in average heat flux with increasing break-point temperature, pointing out the influence of the thickness of the solid flux layer, which increases as the break-point temperature increases. ${ }^{[33]}$

From the literature review, it is apparent that there are many factors influencing heat transfer through the slag film formed in the continuous casting mold, and although many techniques have been developed for their study, still no general agreement has been reached about what film characteristics are the most crucial for differentiating mold powders for low- and medium-carbon steels. This study conjectures that the slag film that infiltrates between the mold and steel at the meniscus is exposed to quick cooling on the mold side where it freezes, forming a glassy layer, as confirmed recently by Park et al. ${ }^{[21]}$ On the strand side, the film is expected to remain liquid. Thus, hot and cold crystallization (i.e., from molten and glassy states, respectively) must take place within the slag film formed in the continuous casting mold; cold crystallization is known as devitrification. Which of the two mechanisms is more important is still not precisely known. However, since devitrification occurs in a solid that would be next to another (mold plate), the phenomenon of devitrification that would modify the contact between their surfaces must certainly be relevant. For this reason, in the present study, the authors chose to work with a glassy slag as the starting material and to use temperatures below the liquidus temperatures of the slags investigated. However, as found by thermal analysis of devitrifying samples, partial melting must occur in the disks subjected to $T_{\mathrm{c}} \geq 1273 \mathrm{~K}\left(1000{ }^{\circ} \mathrm{C}\right)$. Thus, the system designed contains essential features for studying how devitrification affects heat transfer. This study uses a sandwiching method to determine the overall effective thermal resistance, $R_{\mathrm{T}}$, between two metallic surfaces at different temperatures and separated by an initially glassy slag disk, made from mold powders for casting low, A, and medium, B, carbon steels in CSP molds. Additionally, from scanning electron microscopy examination of devitrified disks and confocal laser scanning microscope (CLSM) real-time observations of devitrifying glass parallelepipeds, it is conjectured that the considerably greater $R_{\mathrm{T}}$ exhibited by powder $\mathrm{B}$ is related to the porous structure resulting from crystallization. Powder A, which experiences a similar degree of crystallization, does not exhibit a large porosity. Furthermore, $R_{\mathrm{T}}$ values estimated from plant data, according to a mathematical model, suggest that the thickness of films forming in the actual process is considerably thinner than those used in the experimental tests.

\section{EXPERIMENTAL}

\section{A. Test Rig, Conditions, and Procedure}

Measurement of heat flux through a slag film with a prescribed thickness is done using a steady-state induction-heating-based technique, which allows maintaining constant the temperature distribution of an Inconel crucible while heat is extracted from it by a water-cooled $\mathrm{Cu}$ finger. This setting is schematically illustrated in Figure 1(a), which shows a crucible with a three turns coil surrounding the lower part of its base and a water-cooled $\mathrm{Cu}$ finger that is supported by a vertical positioning stage that provides micrometric displacement. A high-frequency generator, 50 to $450 \mathrm{kHz}$ (Luzars URF-5, ASEPSA S.A. de C.V., QRO, Mexico), with a nominal output power of $5 \mathrm{~kW}$ and a maximum root-mean-square output current of $60 \mathrm{~A}$, is used for induction heating. The generator includes a port for external control through the application of a voltage input in the range of 0 to $5 \mathrm{VDC}$, for 100 pet of the output power range. A proportional-integral-differential (PID) digital controller (E5AK-AA2-500, Omron Corp., Kyoto, Japan) provides the required input voltage by measuring the temperature of the control thermocouple and comparing it with the specified set point value. Based on their differences and the defined PID gains, the controller adjusts the voltage to supply the required output power of the generator to maintain the control temperature at the prescribed value.

As displayed in Figure 1(b), the crucible is instrumented with three thermocouples: the control thermocouple, $T_{\mathrm{c}}$, is located at $12 \mathrm{~mm}$ from the top surface of the base; and the measuring thermocouples are at 2 and 


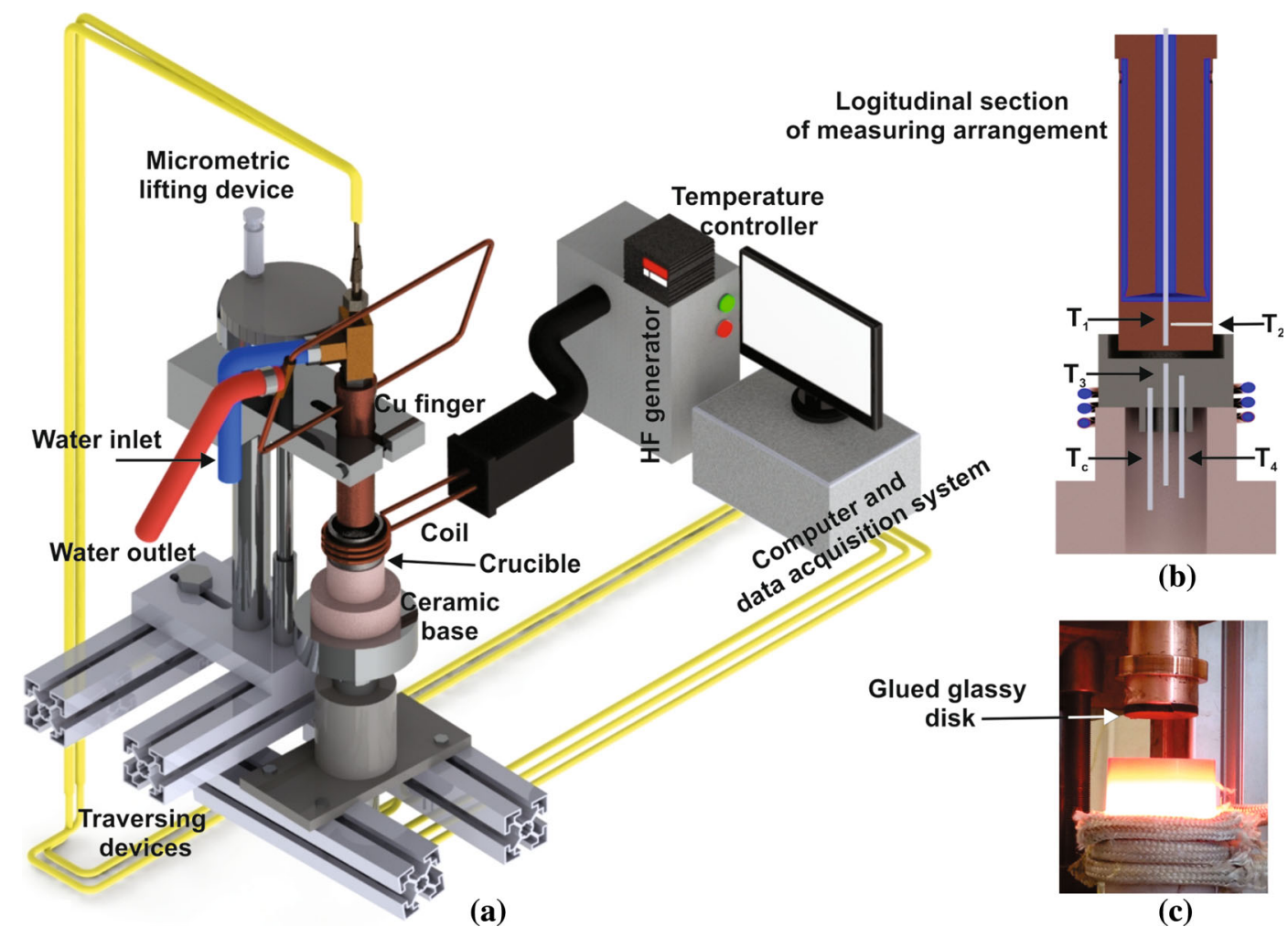

Fig. 1-(a) Schematic of experimental rig showing water-cooled copper finger, controlled induction-heated Inconel crucible, positioning stage, and instrumentation; $(b)$ detailed view of a heat flux measuring assembly; and $(c)$ photograph showing a glassy slag disk before descending to touch the top surface of the crucible base.

$7 \mathrm{~mm}$ from it and are denoted as $T_{3}$ and $T_{4}$, respectively. The thermocouples are sheathed unground $\mathrm{K}$ type with 0.4 -mm-diameter wires housed inside a 1.58 -mm-diameter Inconel tube, which are concentrically placed at 3 $\mathrm{mm}$ from the centerline. In regard to the $\mathrm{Cu}$ finger, it is seen from the figure that this has a central water input channel and that the water then flows radially parallel to the tip to exit through a channel ring. The average water superficial velocity in the horizontal channel is $14.3 \mathrm{~m} / \mathrm{s}$. The finger uses two thermocouples such as those installed in the crucible: one located at the centerline at $3 \mathrm{~mm}$ from the tip and another at $8 \mathrm{~mm}$ from it and slightly off-center; these are denoted in the figure as $T_{1}$ and $T_{2}$, respectively. The thermocouple temperatures and induction power are sampled every 5 seconds by the data acquisition system illustrated in Figure 1(a). The thermocouples were held firmly in place by pressure caps.

The internal and external diameters of the crucible are 39 and $43 \mathrm{~mm}$, respectively, and the finger diameter is 30 $\mathrm{mm}$. The crucible wall height is $10 \mathrm{~mm}$, and its base is $18-\mathrm{mm}$ thick. The first turn of the coil is located $\sim 2 \mathrm{~mm}$ below the level of the control thermocouple to minimize radial heat transfer over the instrumented portion of the crucible base. Thus, for one-dimensional steady-state heat transfer, the effective heat flux, $q_{\text {eff }}$, through the slag disk sandwiched between the crucible and the finger is calculated as

$$
q_{\mathrm{eff}}=k_{\mathrm{In}} \frac{T_{4}-T_{3}}{d_{4-3}}
$$

where $k_{\text {In }}$ is the thermal conductivity of Inconel at the average temperature between $T_{3}$ and $T_{4}$, and $d_{4-3}$ is the thermocouple separation. The thermal conductivities of the Inconel and copper are listed in Table I, together with the control temperatures used in the experiments and with the thickness range of the glassy slag disks. For verifying the correct installation of thermocouples $T_{3}, T_{4}$, and $T_{\mathrm{c}}$, a high-temperature surface thermocouple was put on top of the crucible base to compare the measured temperature with $T_{\mathrm{s}}$ calculated from Eq. [5]; a temperature difference smaller than 2 pct was obtained when the crucible thermocouples made good contact with the top surface of the wells.

For simulating the devitrification and heat flux that take place when liquid slag is quenched on the surface of the mold forming a glassy film that remains attached to it while receiving heat from the strand, in the experiments, a glassy disk is glued to the fingertip, as seen in Figure 1(c). While the crucible is heated to the desired $T_{\mathrm{c}}$, the disk is shielded from radiation; once $T_{\mathrm{c}}$ stabilizes, the disk is rapidly lowered and gently rested on the top surface of the crucible base. The power is turned off after 10,800 seconds ( 3 hours), and the $\mathrm{Cu}$ finger is risen to blow $\mathrm{N}_{2}$ for cooling the devitrified disk and to recover 


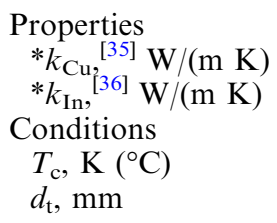

$399.94-0.0534(T-300)$

$11.236-0.0176(T-293)$

$973,1073,1173,1273,1373,1423(700,800,900,1000,1100,1150)$

0.7 to 3.2

* The equations were obtained by linear regression of the data reported in the references, for the temperature ranges indicated.

Table II. Basicity and Composition of Glass Samples Prepared from Mold Powders A and B; the F was Analyzed by the Seel Method and the Other Elements by AAS or ICP

\begin{tabular}{|c|c|c|c|c|c|c|c|c|c|}
\hline Powder & Pct $\mathrm{CaO} / \mathrm{Pct} \mathrm{SiO}_{2}$ & Pct $\mathrm{SiO}_{2}$ & Pct $\mathrm{CaO}$ & Pct $\mathrm{MgO}$ & Pct $\mathrm{Al}_{2} \mathrm{O}_{3}$ & Pct $\left(\mathrm{Na}_{2} \mathrm{O}+\mathrm{K}_{2} \mathrm{O}\right)$ & Pct $\mathrm{Fe}_{2} \mathrm{O}_{3}$ & Pct $\mathrm{MnO}$ & Pct F \\
\hline $\mathrm{A}$ & 0.94 & 34.6 & 32.5 & 3.1 & 2.6 & 12.3 & 0.8 & 0.05 & 6.8 \\
\hline B & 1.09 & 29.7 & 32.3 & 2.8 & 5.9 & 9.5 & 0.8 & 2.8 & 7.9 \\
\hline
\end{tabular}

AAS, atomic absorption; ICP, inductively coupled plasma.

as much as possible for its examination. The diameter of the slag disk matches that of the $\mathrm{Cu}$ finger, and the distance between the fingertip and the crucible base is equal to its thickness. The difference between the diameter of the disk and the internal diameter of the crucible leaves a separation ring of $4.5 \mathrm{~mm}$, filled with hot air, which must favor one-dimensional heat transfer through the disk thickness.

In preliminary tests intended to determine the pressure exerted on the disk upon placement on the crucible base, cold trials were carried out using Fujifilm Prescale tactile pressure indicating sensor film of extreme low type (measuring range 0.49 to 1.96 bars, i.e., lowest range available). ${ }^{[34]}$ It was found that the pressure exerted on the disk, to avoid severe crushing, was below the lower limit of the detection range, which corresponds to a steel head of $0.64 \mathrm{~m}$. Since during disk placement the descent of the finger was stopped once the separation of the finger tip from the crucible was equal to $d_{\mathrm{t}}$-at which point certain opposition to descent was felt on the positioning stage - the pressure on the disk must be of the order of that sensed around the meniscus. The same lowering procedure was applied throughout all experiments to maintain the same degree of contact of the disk with the metallic surfaces.

\section{B. Materials and Glass Sample Preparation}

Commercial mold powders used for casting CSP thin slabs were selected for the study. A bag of each of the powders A and B was decarburized in small batches by introducing them, in porcelain dishes, into a resistance muffle furnace, at $923 \mathrm{~K}\left(650{ }^{\circ} \mathrm{C}\right)$ for 16 hours; this period was interrupted twice to mix the powder for ensuring complete removal of free $\mathrm{C}$. The decarburized powder was ground in an $\mathrm{Al}_{2} \mathrm{O}_{3}$ ball mill to mesh -100 $(\leq 149 \mu \mathrm{m})$.

In the case of mold powder $\mathrm{A}$, samples of $\sim 70 \mathrm{~g}$ were melted in a graphite crucible heated to $1573 \mathrm{~K}\left(1300^{\circ} \mathrm{C}\right)$ in a muffle furnace and maintained for 300 seconds (5 minutes) for homogenization. Then the muffle was opened to cool the chamber rapidly to around the slag liquidus temperature $\left[1473 \mathrm{~K}\left(1200{ }^{\circ} \mathrm{C}\right)\right]$ before transferring the crucible to a closed insulated chamber where it cooled to $\sim 623 \mathrm{~K}\left(350^{\circ} \mathrm{C}\right)$ in $\sim 1800$ seconds $(30$ minutes). Once this temperature was reached, the crucible was returned to a muffle at the same temperature and left to cool to ambient, with the muffle closed. This procedure produces sound fully glassy rods ( $~ 0.10 \mathrm{~m}$ height and $0.03 \mathrm{~m}$ diameter). In the case of mold powder $B$, the same procedure leads to fully crystallized rods. The method that is found suitable for powder B consists in casting the melt at $1573 \mathrm{~K}$ $\left(1300{ }^{\circ} \mathrm{C}\right)$ into a brass mold preheated to $\sim 623 \mathrm{~K}$ $\left(350^{\circ} \mathrm{C}\right)$, and once the slag overflows the mold, a lid, at the same temperature, is put on it; the amount cast is just sufficient to form disks of near final thickness. ${ }^{[34]}$ After 600 seconds (10 minutes), the heating elements of the mold and lid are turned off. Interrupted quenching of small amounts of slag B from $\sim 1573 \mathrm{~K}$ to $623 \mathrm{~K}$ $\left(1300{ }^{\circ} \mathrm{C}\right.$ to $350{ }^{\circ} \mathrm{C}$ ) ensures fully glassy disks are obtained. The glassy state of the disks is confirmed by X-ray diffraction (XRD), and each procedure produces material that withstands cutting, grinding, and polishing; cutting is necessary only in the case of bars of slag A. ${ }^{\text {34] }}$ The average chemical compositions of the glasses prepared from powders $\mathrm{A}$ and $\mathrm{B}$ are reported in Table II. To carry out the heat flux tests, the transverse surfaces of disks were roughed down with 800 and 1200 emery papers and were then polished up to colloidal silica suspension of $0.05 \mu \mathrm{m}$ to smooth them. The photograph in Figure 2(a) shows an example of a disk used for heat flux determination.

\section{Observation of Simulated Mold Flux Interface}

The hot surface of CSP molds reaches maximum temperatures between $\sim 653 \mathrm{~K}$ and $803 \mathrm{~K}\left(\sim 380{ }^{\circ} \mathrm{C}\right.$ and 


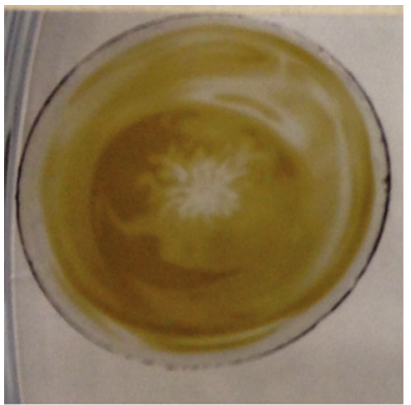

(a)

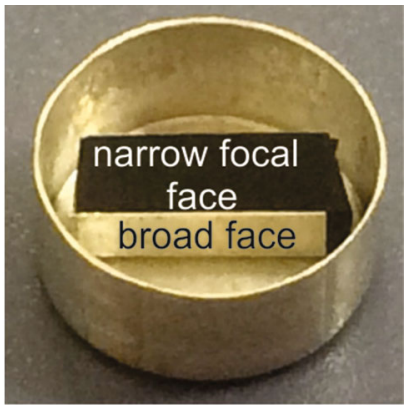

(b)
Fig. 2-Photographs of $(a)$ a glassy slag disk used in heat flux measurement experiments; and (b) glassy slag parallelepiped incased in a platinum u-shaped sheet, used for observations in CLSM.

$530{ }^{\circ} \mathrm{C}$ ) during casting at speeds between 4 and $6 \mathrm{~m} /$ min. ${ }^{[37,38]}$ Thus, in the present study, it is conjectured that observation of the motion of a slag surface, devitrifying at those temperatures, in relation to a stationary surface parallel to it would shed light on the formation of the gap - due to shrinkage - that has been claimed so profusely in the literature. To carry out these observations, glass samples in the form of parallelepipeds $2 \times 6 \times 4 \mathrm{~mm}^{3}$ (thickness $\times$ width $\times$ height) are prepared. These glassy pieces are encased in $\mathrm{Pt}$ foil that is bent in the shape of a " $u$ " around their wide faces and base, as shown in Figure 2(b); the broad faces and narrow face are polished up to colloidal silica suspension of $0.05 \mu \mathrm{m}$. As seen in the figure, the Pt-glass arrangement is then placed inside a $\mathrm{Pt}$ crucible $(8-\mathrm{mm}$ diameter) for observation with a high-temperature CLSM system (VL2000DX, Yonekura Mfg. Co. Ltd., Osaka, Japan).

Observation by CLSM is done at $698 \mathrm{~K}, 823 \mathrm{~K}$, and $973 \mathrm{~K}\left(425{ }^{\circ} \mathrm{C}, 550{ }^{\circ} \mathrm{C}\right.$, and $\left.700{ }^{\circ} \mathrm{C}\right)$ using a thermal cycle that consists of heating to $673 \mathrm{~K}\left(400{ }^{\circ} \mathrm{C}\right)$ at $50 \mathrm{~K} / \mathrm{min}$ $\left(50{ }^{\circ} \mathrm{C} / \mathrm{min}\right)$, where it is held 20 seconds and then is heated to the desired temperature at $87 \mathrm{~K} / \mathrm{min}\left(87^{\circ} \mathrm{C} / \mathrm{min}\right)$, where it is maintained for 10,800 seconds ( 3 hours) before cooling to room temperature at $600 \mathrm{~K} / \mathrm{min}\left(600^{\circ} \mathrm{C} / \mathrm{min}\right)$. The observation region includes the cross section of the $\mathrm{Pt}$ foil, an edge of the slag parallelepiped (formed by the observation plane and a vertical broad face), and the gap. This region allows visualization of the changes occurring across the width of the gap left between the Pt foil and the edge of the parallelepiped, revealing how the surface of the broad face of the glassy slag moves in relation to the surface of the Pt sheet.

\section{Differential Scanning Calorimetry and XRD Tests}

Nonisothermal simultaneous differential scanning calorimetry/thermogravimetric analysis (DSC/TGA) tests are conducted using a TGA/DSC3 + apparatus (Mettler-Toledo Inc., CHE) for determining the temperatures of devitrification reactions and the melting range of slags $\mathrm{A}$ and $\mathrm{B}$. The instrument is a heat flux type DSC that is regularly calibrated. Heat flow, temperature difference, and weight variations associated with the transformations taking place in initially glassy slag samples are recorded as a function of temperature and time. The thermal cycle consists of heating the sample at $20 \mathrm{~K} / \mathrm{min}\left(20{ }^{\circ} \mathrm{C} / \mathrm{min}\right)$ from $473 \mathrm{~K}$ to $1473 \mathrm{~K}$ $\left(200{ }^{\circ} \mathrm{C}\right.$ to $1200{ }^{\circ} \mathrm{C}$ ) for slag $\mathrm{A}$ and to $1498 \mathrm{~K}\left(1225^{\circ} \mathrm{C}\right)$ for $\mathrm{B}$, followed by holding for 600 seconds (10 minutes) and then cooling to $473 \mathrm{~K}\left(200{ }^{\circ} \mathrm{C}\right)$ at the same absolute rate, and finally freely cooling to ambient. In this work, only the heating portion of the thermoanalysis trace is presented in Section IV-C. The samples used are in powder form with a particle size range of 53 to $63 \mu \mathrm{m}$ and a weight of $65 \pm 0.5 \mathrm{mg}$. In all the tests, empty $\mathrm{Pt}$ crucibles, $0.006-\mathrm{m}$ diameter $\times 0.004-\mathrm{m}$ height, such as those employed for the problem material, are used as reference, and the purging gas is ultrahigh purity $\mathrm{Ar}$ flowing at $0.83 \mathrm{~mL} / \mathrm{s}(50 \mathrm{~mL} / \mathrm{min})$.

The samples resulting from the different tests-heat flux measuring, CLSM, and DSC-were analyzed by XRD using a Philips X'Pert diffractometer, with a $\theta-2 \theta$ Bragg-Bretano geometry. In order to determine the precipitated crystalline phases, diffraction data collection was carried out by $\mathrm{Cu}$ radiation in the angular range of 7 to $100 \mathrm{deg} 2 \theta$ with steps of $0.025 \mathrm{deg} 2 \theta$ and a counting time of $16.5 \mathrm{~s} / \mathrm{step}$.

\section{ANALYSIS OF PLANT DATA}

To compare the total effective thermal resistance, $R_{\mathrm{T}}$, determined in the laboratory with values estimated from industrial trials involving CSP molds, computational calculations reported by the authors ${ }^{[37]}$ are used. The mold studied is straight in the casting direction and has a funnel-shaped section across its central upper part. The main characteristics and operating conditions of the mold employed are given in detail elsewhere, ${ }^{[37]}$ and although in the present operation the mold has been widened to adapt it to a liquid core reduction machine, the mold powders selected continue in use.

To determine the heat flux distribution in the mold, thermocouples were inserted into specially designed wells. Details about the thermocouples, their installation, and the signal registration are described in Reference 37 . The number of thermocouples installed in each broad face was 32 , and several were distributed close to the steel meniscus and at the end of the funnel. Temperature measurements over steady-state operation periods were used to determine the mold hot-face temperature, $T_{\mathrm{m}}$, and heat flux, $q_{\mathrm{m}}$, distributions by solving iteratively the direct steady-state two-dimensional heat conduction problem using the control volume method. ${ }^{[37]}$

The temperature distribution in the strand is determined by solving the heat conduction conservation equation for a steel slice moving at the casting speed. While the slice is in the mold, the boundary conditions at its faces are specified according to the $q_{\mathrm{m}}$ distributions estimated by the procedure described in the previous paragraph. At the symmetry planes of the slice, the heat fluxes are zero. The solution of the energy conservation equation for the slice allows calculation of, among other parameters, the slab surface temperature $T_{\mathrm{sh}} \cdot{ }^{[37]}$ Hence, from the difference in local surface temperatures 
between the strand and the mold and from the local heat flux transferred between the two, the overall effective thermal resistance is estimated as

$$
R_{\mathrm{T}}=\frac{T_{\mathrm{sh}}-T_{\mathrm{m}}}{q_{\mathrm{m}}}
$$

and linear interpolation is used to determine the spatial distribution.

\section{RESULTS AND DISCUSSION}

\section{A. Temperature and Heat Flux Results}

The changes of crucible $\left(T_{3}, T_{4}, T_{\mathrm{c}}\right)$ and finger $\left(T_{1}, T_{2}\right)$ temperatures with time are shown in Figure 3 for a typical experiment; the case presented corresponds to a disk of slag A with thickness $d_{\mathrm{t}}=0.79 \mathrm{~mm}$ and a $T_{\mathrm{c}}=1173 \mathrm{~K}\left(900^{\circ} \mathrm{C}\right)$. It is seen that during heating to $T_{\mathrm{c}}$, the three thermocouples in the crucible evolve closely, and during the stabilization period, the three reach the same temperature. When the finger descends with the glass disk to rest it on the crucible base, the temperatures of the thermocouples drop rapidly and then rise to stabilize to their final values; $T_{\mathrm{c}}$ returns to the prescribed value, and the other two reach values that are functions of $T_{\mathrm{c}}, d_{\mathrm{t}}$, and the type of slag used, A or B. Simultaneously, the temperatures of the finger rise and also reach stable values. Due to the much smaller thermal conductivity of Inconel in relation to $\mathrm{Cu}$, the temperature differences in the crucible are much larger than those in the finger, as seen from the figure. Therefore, $T_{3}$ and $T_{4}$ are used to estimate the effective heat flux across the measuring arrangement, according to Eq. [1]. From the figure, it is noticed that the separation between thermocouple temperatures remains constant after a short time of lowering the sample, indicating that the heat flux across the film thickness stays constant and suggesting that its characteristics, e.g., degree of devitrification, porosity, and roughness,

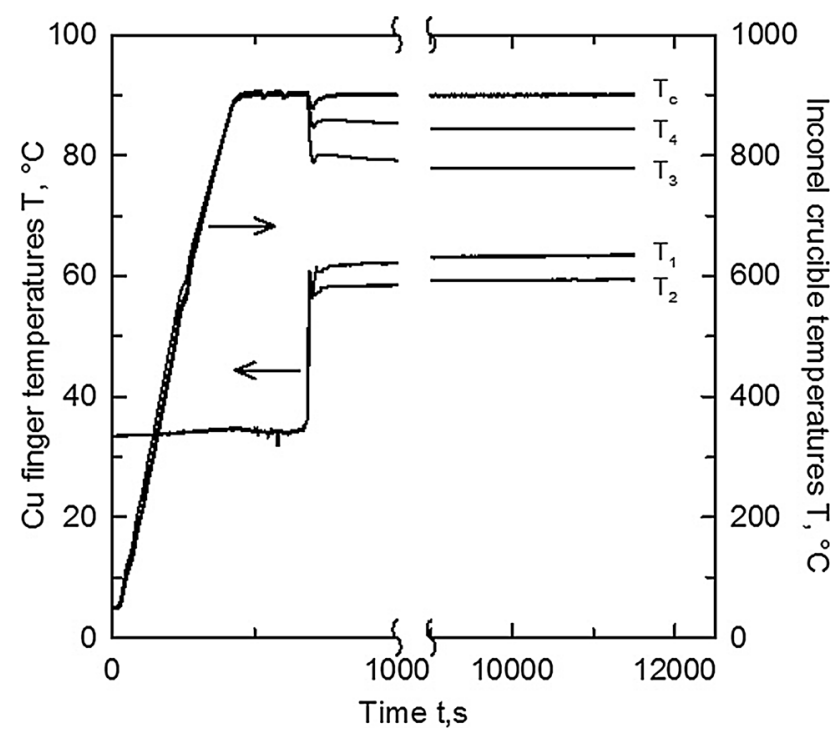

Fig. 3-Typical temperature evolution at thermocouple positions. are established rapidly. This is supported by previous results indicating that isothermal devitrification of both glasses, $\mathrm{A}$ and $\mathrm{B}$, occurs fast in the temperature range of $923 \mathrm{~K}$ to $1398 \mathrm{~K}\left(650{ }^{\circ} \mathrm{C}\right.$ to $\left.1125^{\circ} \mathrm{C}\right) .{ }^{[39]}$

In the experiments, the $\mathrm{Cu}$ fingertip operates relatively cold; in the most extreme condition (which corresponds to $T_{\mathrm{c}}=1423 \mathrm{~K}\left(1150{ }^{\circ} \mathrm{C}\right), d_{\mathrm{t}}=0.73 \mathrm{~mm}$, and glass disk A), the temperature reaches only $\sim 345 \mathrm{~K}\left(\sim 72^{\circ} \mathrm{C}\right)$. Thus, at the end of all the experiments, the top surface of the disks maintains a polished appearance. ${ }^{[34]}$ Also, the $\mathrm{Cu}$ fingertip maintains a smooth condition, which is preserved by wiping out the oxide before each use. The state of these surfaces suggests that the gap between the disk and the fingertip is negligible, and that the temperature profile across the measuring arrangement should look like that illustrated in Figure 4, with the interfacial resistance located on the hot side in contact with the crucible.

The effective heat flux-conduction plus radiation-calculated from Eq. [1] is plotted as a function of slag disk thickness in Figures 5(a) and (b) for mold slags $\mathrm{A}$ and $\mathrm{B}$, respectively, and different $T_{\mathrm{c}}$. As seen from the figures, $q_{\text {eff }}$ decreases with the increase in $d_{\mathrm{t}}$, as expected from the increase in resistance to heat transfer by both mechanisms. Furthermore, as anticipated, the figures show that $q_{\mathrm{eff}}$ increases as $T_{\mathrm{c}}$ rises.

\section{B. Overall Thermal Resistance}

The total thermal resistance between the top surface of the crucible base and the $\mathrm{Cu}$ fingertip, which are at temperatures $T_{\mathrm{s}}$ and $T_{\mathrm{m}}$, respectively, can be expressed as

$$
R_{\mathrm{T}}=\frac{T_{\mathrm{s}}-T_{\mathrm{m}}}{q_{\mathrm{eff}}}
$$

where the $q_{\mathrm{eff}}$ is obtained from Eq. [1] and $T_{\mathrm{s}}$ and $T_{\mathrm{m}}$ are calculated from the following equations:

$$
\begin{gathered}
T_{\mathrm{m}}=T_{1}+q_{\mathrm{eff}} \frac{d_{\mathrm{m}}}{k_{\mathrm{Cu}}} \\
T_{\mathrm{s}}=T_{3}-q_{\mathrm{eff}} \frac{d_{\mathrm{s}}}{k_{\mathrm{In}}}
\end{gathered}
$$

The total effective thermal resistance is composed of the effective resistance of the mold slag disk and the contact resistance of the interface between the disk and the crucible. Figures 6(a) and (b) show measured values of $R_{\mathrm{T}}$ as a function of disk thickness for mold powder slags $\mathrm{A}$ and $\mathrm{B}$, respectively, and different $T_{\mathrm{c}}$. It is seen that the measured $R_{\mathrm{T}}$ values, at a given $T_{\mathrm{c}}$, are reasonably fitted by linear regression equations that can be expressed as

$$
R_{\mathrm{T}}=R_{\mathrm{int}}+\frac{d_{\mathrm{t}}}{k_{\mathrm{eff}}}
$$

where $R_{\text {int }}$ is the interfacial thermal resistance and $k_{\text {eff }}$ is an effective thermal conductivity of the film; these terms correspond to the intersect and inverse of the 
slope of the lines, respectively. Figures 6(a) and (b) do not show a clear difference in $R_{\text {int }}$ between the mold powder slags A and B; furthermore, the intercepts of the lines at the origin do not follow a trend with $T_{\mathrm{c}}$. Instead, $R_{\text {int }}$ shows unsystematic changes that must be associated to random variations in slag disk-Inconel contact. Over the $T_{\mathrm{c}}$ range studied, the slag disks present softening or partial melting that must be

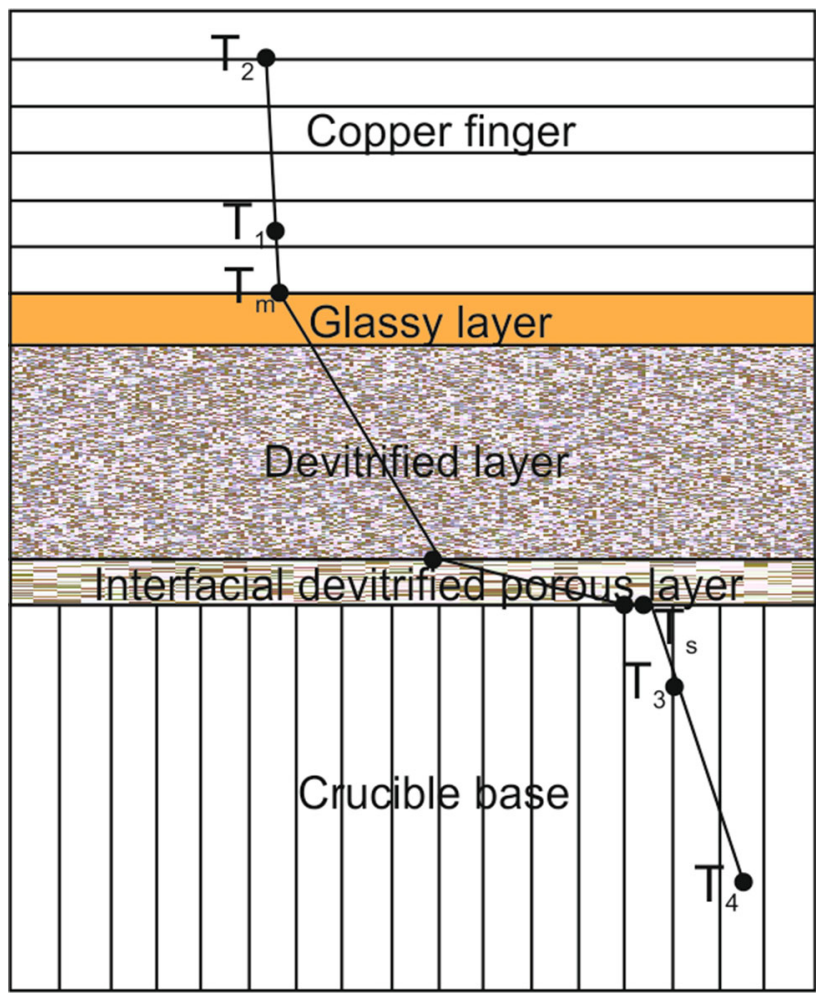

Fig. 4-Schematic of temperature distribution across the measuring assembly. responsible for variations in the degree of contact with the crucible base. Furthermore, it is evident that the difference between the two mold powders is associated with the effective resistance of the film $\left(=d_{\mathrm{t}} / k_{\mathrm{eff}}\right)$. This term leads to $R_{\mathrm{T}}$ values for mold slag $\mathrm{B}$ that, on average, over all the conditions, are 33 pct larger than those for mold slag A. As seen in Section IV-C, the main factor contributing to the larger $R_{\mathrm{T}}$ of slag $\mathrm{B}$ must be the much larger porosity that this slag develops during crystallization compared to slag A. Porosity reduces conductivity, both phononic and photonic.

Figures 7(a) and (b) show the measured $R_{\mathrm{T}}$ as a function of the surface temperature $T_{\mathrm{s}}$ of the crucible, for slag films with different thicknesses (within a narrow range). The plots exhibit lower and upper temperature regions, where $R_{\mathrm{T}}$ decreases with the increase in temperature and an intermediate temperature region where $R_{\mathrm{T}}$ varies slightly. These regions must be related to physical changes that occur in the characteristics of the slag layer with temperature, as discussed in Section IV-C.

\section{Characteristics of a Simulated Flux-Mold Interface}

Figures 8 and 9 display CLSM images that include a portion of the narrow face (lower part of photographs) of mold flux slag parallelepipeds; the cross section of the Pt foil (upper part of photographs) that surrounds the sample, as shown in Figure 2(b); and the gap left in between. The photomicrographs show the evolution of initially glassy slag samples of mold powders A and B, respectively, at different times of the treatment period lasting 10,800 seconds ( 3 hours) at (a) $698 \mathrm{~K}\left(425{ }^{\circ} \mathrm{C}\right)$, (b) $823 \mathrm{~K}\left(550{ }^{\circ} \mathrm{C}\right)$, and (c) $973 \mathrm{~K}\left(700{ }^{\circ} \mathrm{C}\right)$. The times recorded in the photographs are measured from the start of the experiment, and the first micrograph of each row corresponds approximately with the instant in which the set point temperature is reached. The dotted line drawn

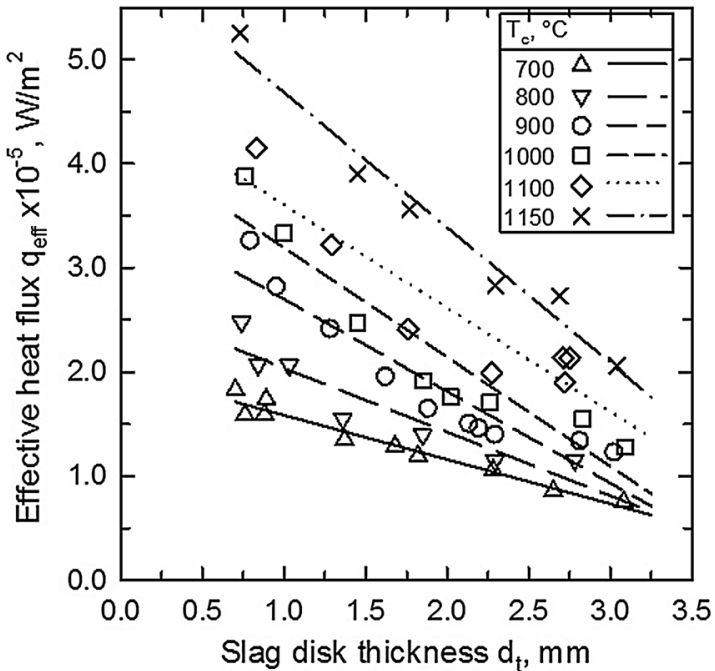

(a)

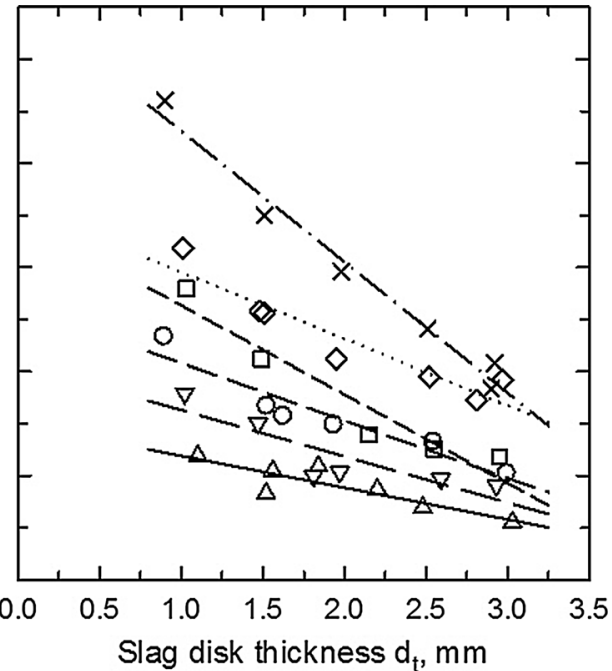

(b)

Fig. 5-Variation of heat flux with slag film thickness for several $T_{\mathrm{c}}$ : (a) slag A and (b) slag B. 


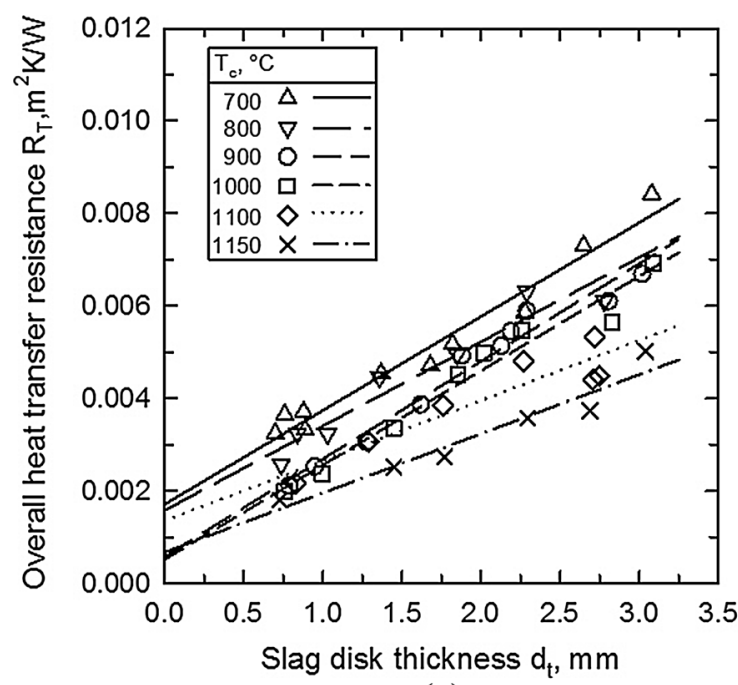

(a)

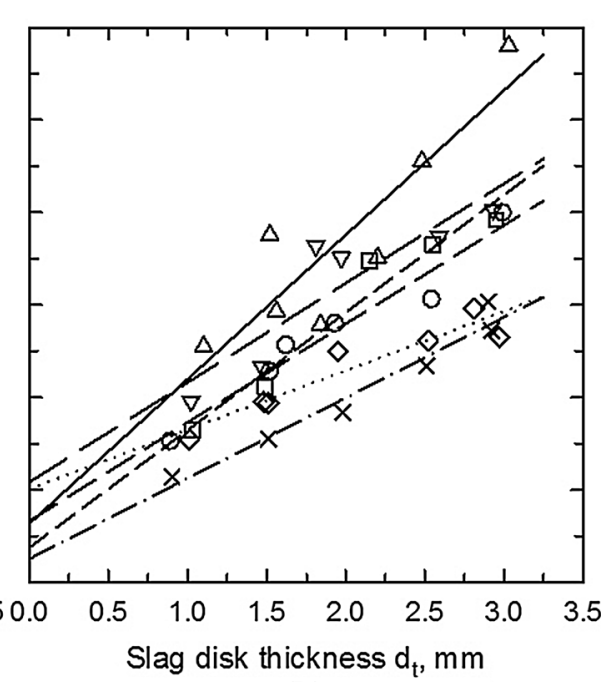

(b)

Fig. 6-Variation of overall effective heat-transfer resistance with slag film thickness for several $T_{\mathrm{c}}$ : $(a)$ slag A and (b) slag B.

from the lower left corner of the Pt foil across images for different times indicates clearly that the wall of $\mathrm{Pt}$ does not move during the treatment and that the change in gap width should be associated with the motion of the wide face of the parallelepiped caused by glass transition or devitrification reactions. The white solid line delineates the border of the narrow face of the sample at a moment close to when the sample reaches the treatment temperature.

For the treatments at $698 \mathrm{~K}\left(425^{\circ} \mathrm{C}\right)$, Figures $8(\mathrm{a})$ and 9(a) show that no great changes happen in the surface of the samples with time; however, a slight inward motion of the border of the narrow face is appreciated for the longest time. The retraction of the border is larger for mold slag B than for A. The inward motion of the border is noticed also by comparing the magnifications displayed in Figures 10(a) and (b), for mold powder B. Another interesting feature is the growth of tiny "spikes" on the broad face of the parallelepiped, as shown in these micrographs, which are magnifications of the regions pointed by the arrows drawn in Figure 9(a). As seen in Figure 10(a), these formations start appearing early in the treatment, and with time, they form a skeletal porous structure, shown in Figure 10(b), that counteracts the shrinkage experienced by the dense body. These spikes could be incipient crystals (crystallites) not detected by XRD, which revealed that the samples of both slags remained amorphous after the treatment. It can be conjectured that if the Pt foil had been touching the wide face of the sample, the spikes would have spread and squashed on the wall, closing the superficial pores (roughness) and avoiding the formation of a gap.

The photographs of the treatments at $823 \mathrm{~K}\left(550{ }^{\circ} \mathrm{C}\right)$, displayed in Figures 8(b) and 9(b) for mold slags A and $\mathrm{B}$, respectively, show rapid changes in the appearance of the narrow face of the parallelepipeds. The surface of mold slag A shows some undulations and fine rugosity uniformly distributed; the bright portion of the image corresponds to the in-focus region of the specimen, and the dark spots are all the out-of-focus regions not reflecting back the light. Again, at this temperature, it is possible to visualize small spikes protruding from the broad face of the specimen soon after it has been reached, as seen in the photograph for $t=692.64$ seconds (which corresponds to 151.33 seconds after reaching the temperature) in Figure 8(b). This layer of crystals nucleating and growing on the surface becomes denser and protrudes farther as time elapses. At the end of the treatment, most of the cuspidine has formed according to the time-temperature-transformation diagram reported elsewhere; ${ }^{40]}$ the X-ray diffractogram obtained for the sample at the end of the treatment is shown in Figure 11(a). The changes in the surface of mold powder B with time are presented in the photomicrographs of Figure 9(b). It is seen that variations in the height of the surface develop rapidly, obscuring the field of view. As the devitrification proceeds, a large portion of the surface enters in focus and it is possible to distinguish superficial pores larger than those formed in slag A. A layer of crystals growing on the broad surface of the specimen is seen protruding. Again, these superficial crystals would spread and squash against the surface of the foil if they had been touching the specimen. This behavior indicates clearly that devitrification would not cause the formation of a shrinkage gap. The X-ray diffractogram obtained for the sample at the end of the treatment is shown in Figure 11(b).

Figures 8(c) and 9(c) display the changes in the appearance of the surface of specimens of slags $\mathrm{A}$ and $\mathrm{B}$, respectively, at $973 \mathrm{~K}\left(700{ }^{\circ} \mathrm{C}\right)$. For mold powder A, globulite-shaped crystals start appearing shortly after reaching the temperature (as shown in the micrograph at $t=631.62$ seconds), and as they grow, they tightly pack, covering the surface. For the longest time $(t=11,282.38$ seconds), it is seen that the crystals 


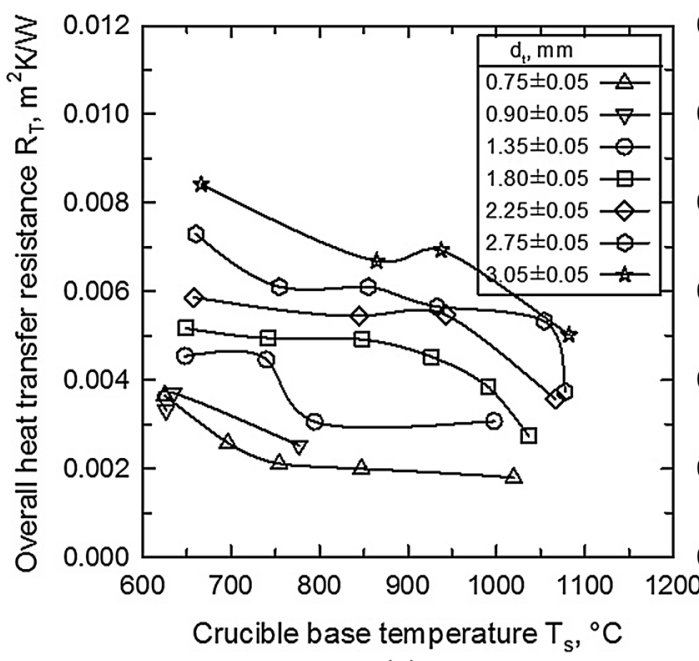

(a)

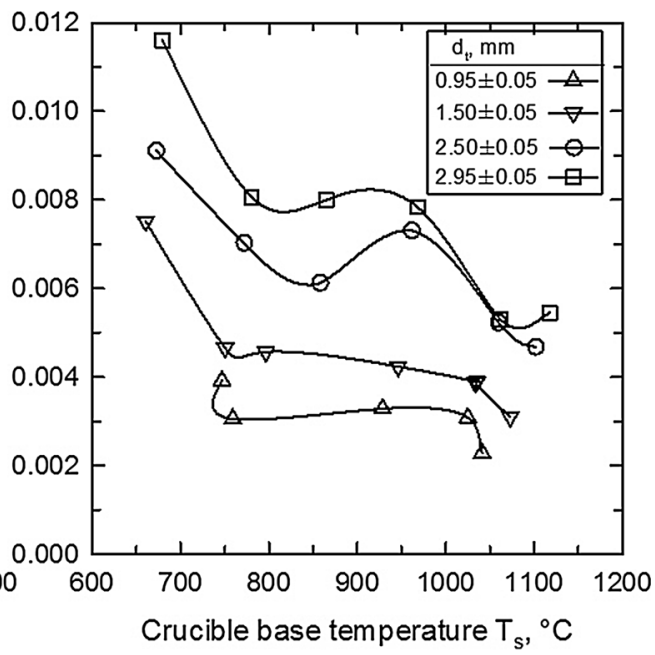

(b)

Fig. 7-Variation of overall effective heat-transfer resistance with $T_{\mathrm{s}}$ for several $d_{\mathrm{t}}$ : $(a)$ slag A and $(b)$ slag B.
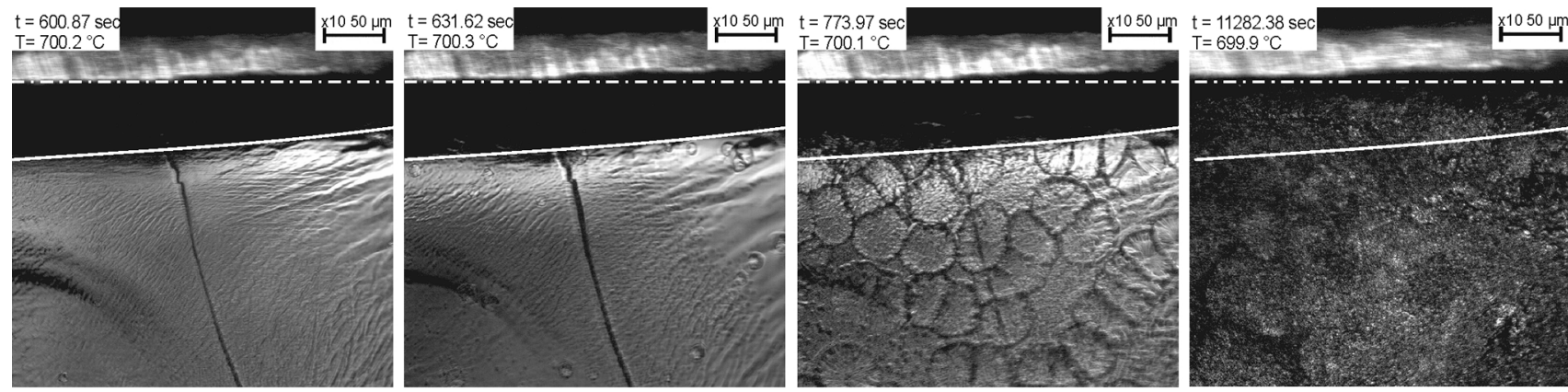

(c)
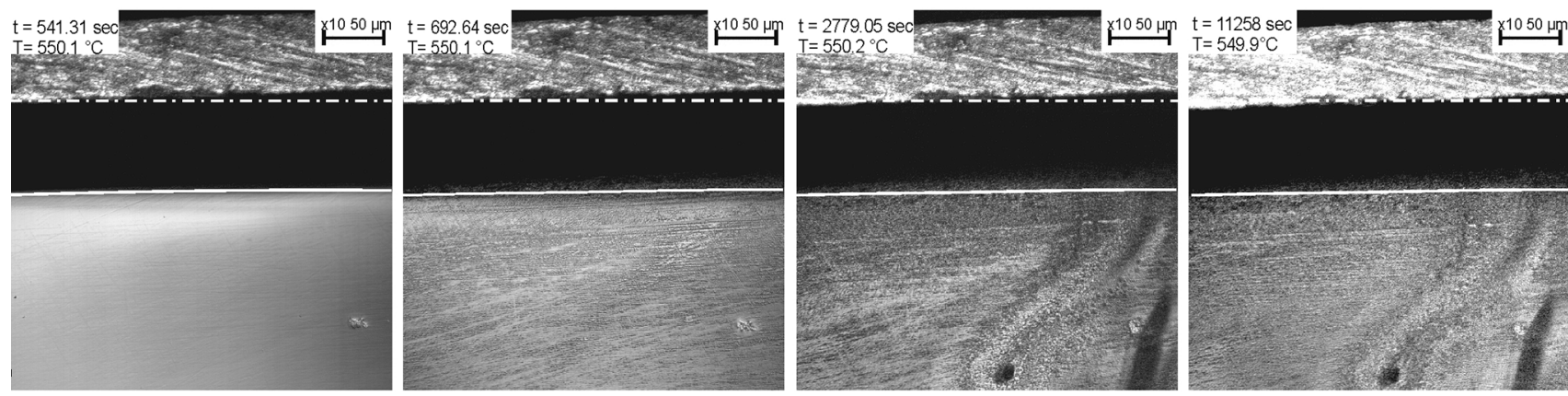

(b)
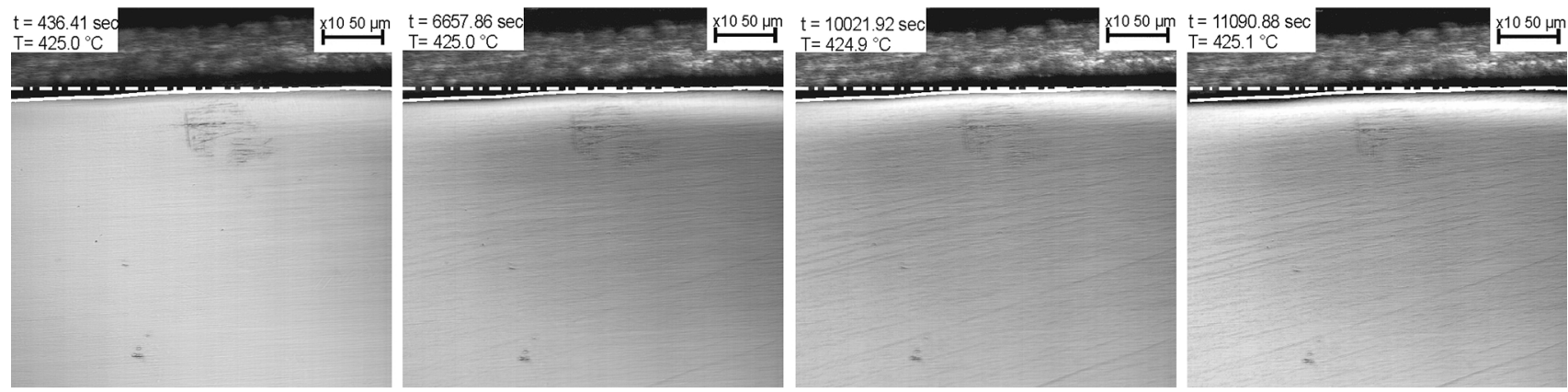

(a)

Fig. 8- CLS microscope images at different times during devitrification of glassy slag A hold at different temperatures: $(a) 698 \mathrm{~K}\left(425{ }^{\circ} \mathrm{C}\right)$, $(b)$ $823 \mathrm{~K}\left(550{ }^{\circ} \mathrm{C}\right)$, and $(c) 973 \mathrm{~K}\left(700{ }^{\circ} \mathrm{C}\right)$. The times appearing are from the start of the experiment. 

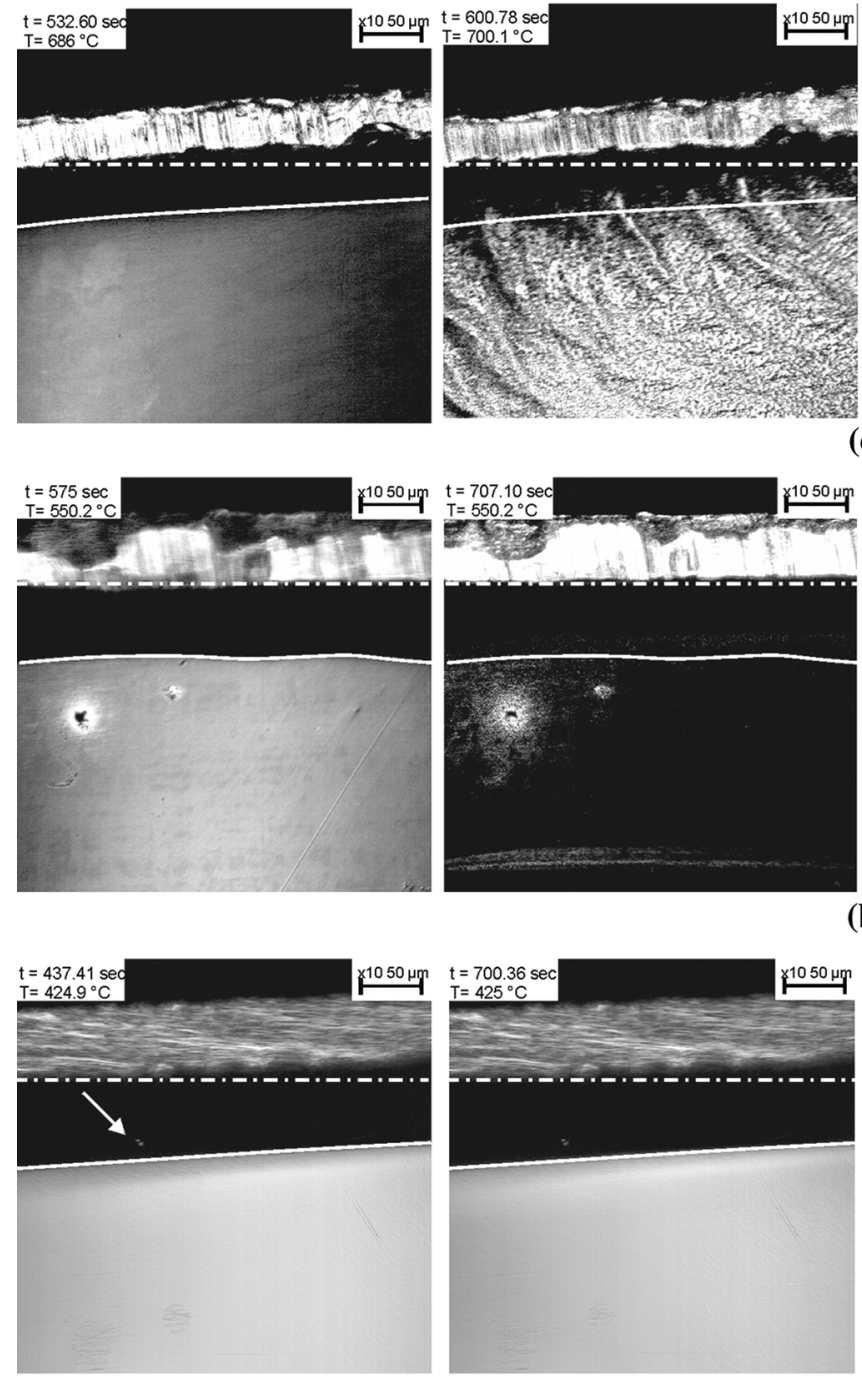

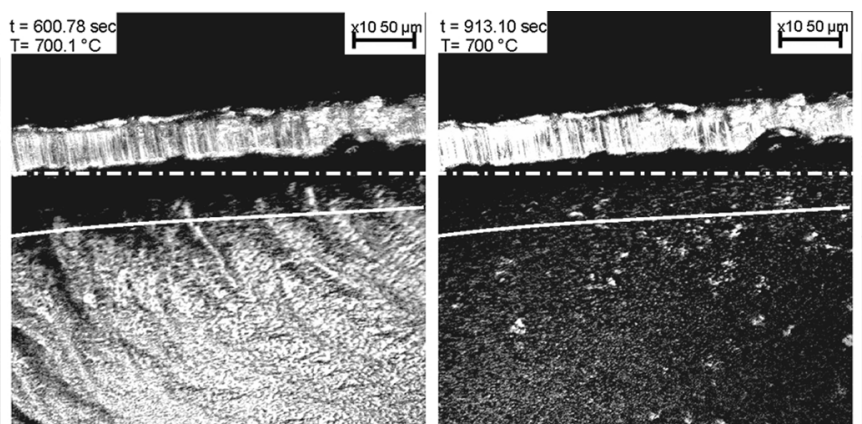

(c)

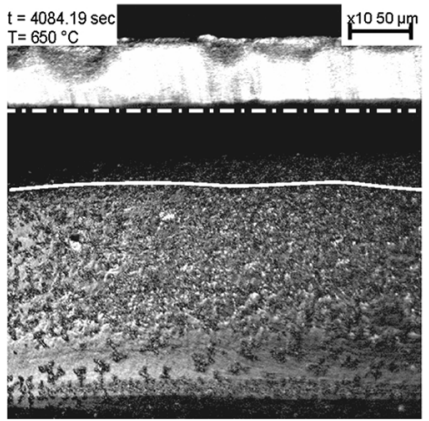

(b)
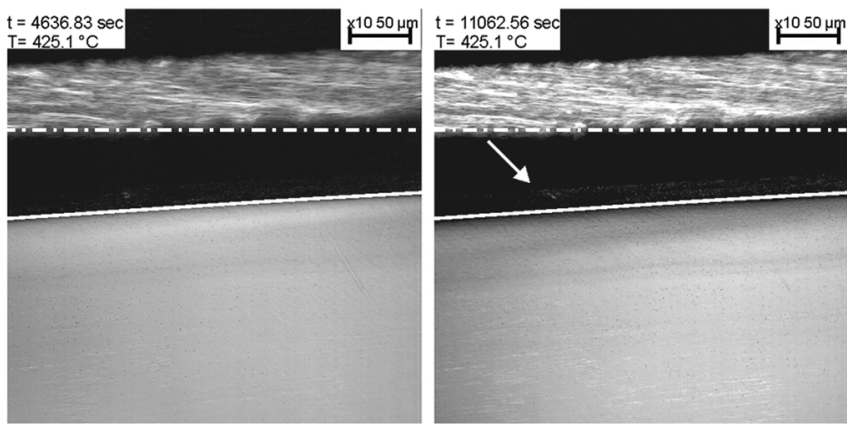

(a)

Fig. 9-CLS microscope images at different times during devitrification of glassy slag B hold at different temperatures: $(a) 698 \mathrm{~K}\left(425{ }^{\circ} \mathrm{C}\right),(b)$ $823 \mathrm{~K}\left(550^{\circ} \mathrm{C}\right)$, and $(c) 973 \mathrm{~K}\left(700^{\circ} \mathrm{C}\right)$. The times appearing are from the start of the experiment.

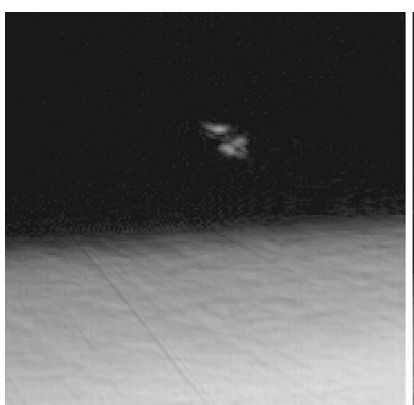

(a)

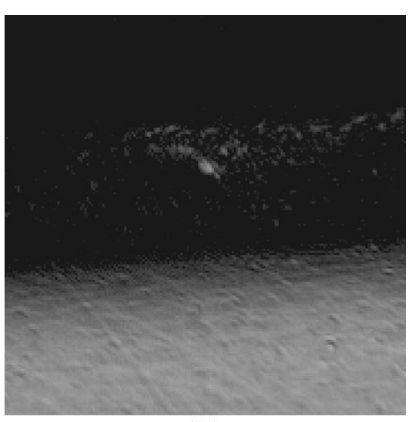

(b)
Fig. 10 - CLSM images of the regions pointed by the arrows in Fig. 9(a) at (a) $t=437.41 \mathrm{~s}$ and $(b) t=11,062.56 \mathrm{~s}$.

growing on the broad face protrude considerably from the original border, forming a layer of fine pores. In the case of mold slag B, it is shortly after reaching the desired temperature that crystals start projecting out of the original border; at $t=600.78$ seconds, feathery-like crystals bulge out of the original border. As time progresses, the protruding crystals become more loosely longest time, just a small proportion of the field of view appears in focus and most of it is dark; out-of-focus regions indicate the presence of large surface and interior pores. The X-ray diffractograms obtained for the samples of both slags at the end of the treatment are shown in Figures 11(a) and (b); the degree of crystallization at this temperature is larger than that for $823 \mathrm{~K}$ $\left(550{ }^{\circ} \mathrm{C}\right) \cdot{ }^{[34]}$

As seen in Table II, there are substantial differences in chemical composition between the two mold fluxes. Particularly, the contents of $\mathrm{SiO}_{2}, \mathrm{Al}_{2} \mathrm{O}_{3}, \mathrm{~F}$, and $\mathrm{MnO}$ are higher in slag $\mathrm{B}$ and the content of $\mathrm{Na}_{2} \mathrm{O}+\mathrm{K}_{2} \mathrm{O}$ is higher in slag A. These differences lead to formation of different crystalline phases from both glasses; only cuspidine $\left(\mathrm{Ca}_{4} \mathrm{Si}_{2} \mathrm{O}_{7} \mathrm{~F}_{1.5}(\mathrm{OH})_{0.5}\right)$ is common to both. Combeite $\left(\mathrm{Na}_{2} \mathrm{Ca}_{2} \mathrm{Si}_{3} \mathrm{O}_{9}\right)$ is the other phase appearing packed, forming a less dense skeletal structure. For the 

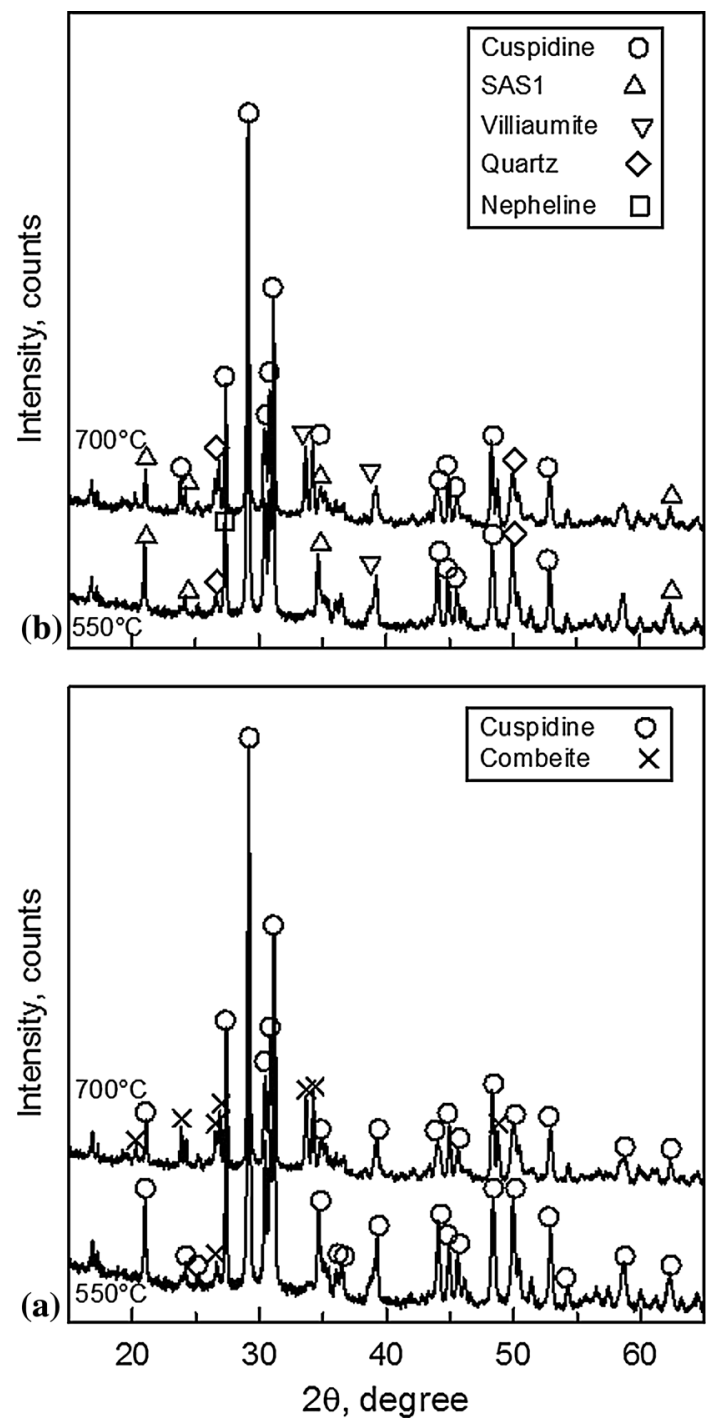

Fig. 11-XRD patterns of powdered parallelepipeds made of glassy slags: $(a) \mathrm{A}$ and $(b) \mathrm{B}$, treated at different temperatures for $10,800 \mathrm{~s}$ $(3 \mathrm{~h})$. SAS1 stands for sodium aluminosilicate, $\mathrm{Na}_{8} \mathrm{Al}_{4} \mathrm{Si}_{4} \mathrm{O}_{18}$.

during devitrification of glass A, while several phases form from glass $\mathrm{B}$; these are sodium aluminosilicate $\left(\mathrm{Na}_{8} \mathrm{Al}_{4} \mathrm{Si}_{4} \mathrm{O}_{18}\right)$, villiaumite $(\mathrm{NaF})$, quartz $\left(\mathrm{SiO}_{2}\right)$, and nepheline $\left(\mathrm{NaAlSiO}_{4}\right)$, as indicated in Figure 11 and elsewhere. ${ }^{[39]}$ The phases appearing during devitrification of slag A form at different temperature intervals during nonisothermal conditions or at different time intervals during isothermal conditions. However, in the case of slag B, all the phases appear simultaneously, i.e., within the same temperature range under nonisothermal conditions or over the same time interval during isothermal devitrification. ${ }^{[39]}$ The heat flow per unit mass released during devitrification of slag $\mathrm{B}$ is larger than in the case of slag $\mathrm{A}$, as seen from the thermal analysis traces presented in Figure 12. Hence, devitrification of slag B is more intense and occurs much faster in slag B than in A, as reported elsewhere. ${ }^{[39]}$ In the case of the simpler devitrifying slag A, it is seen from Figure $8(\mathrm{c}), t=631.62$ seconds, that cuspidine appears

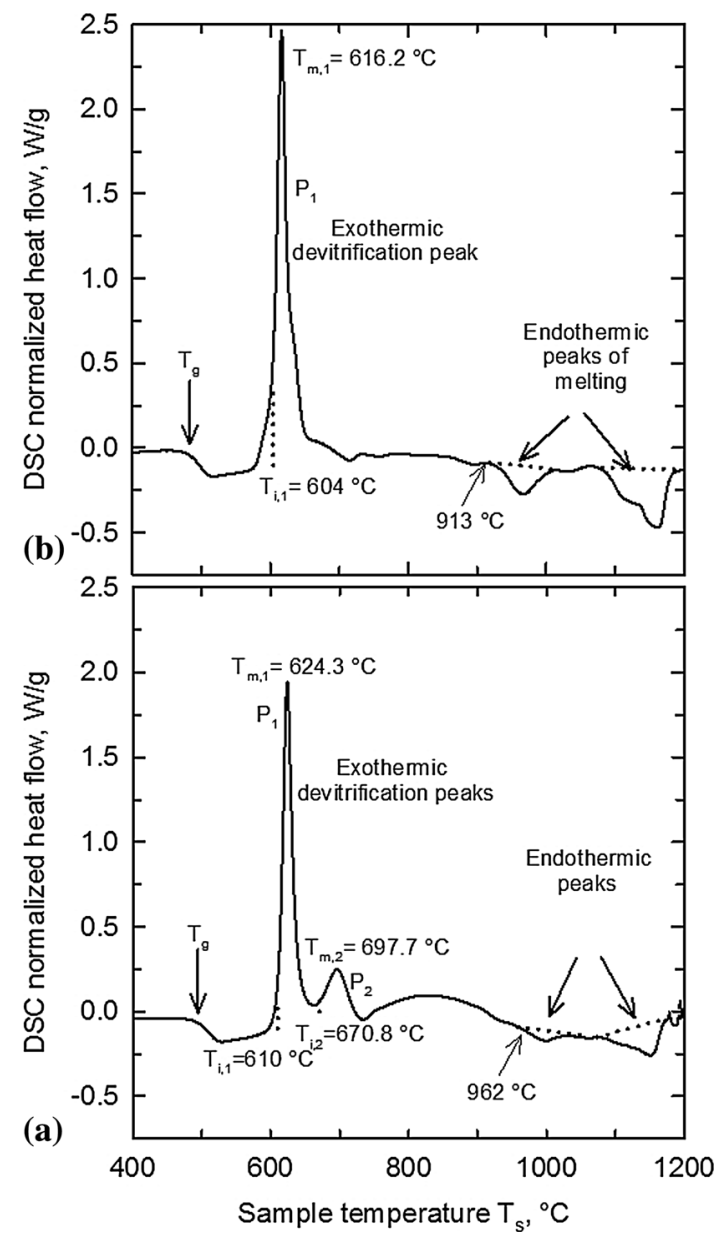

Fig. 12-Nonisothermal DSC trace for devitrification of glassy slags: (a) $\mathrm{A}$ and (b) $\mathrm{B}$, obtained at a heating rate of $20 \mathrm{~K} / \mathrm{min}\left(20^{\circ} \mathrm{C} / \mathrm{min}\right)$.

in the form of globulites that grow uniformly in all directions until they touch each other. Almost all grains appear at the same time, and as time progresses, the size of the grains increases, but only a few additional nuclei appear. Finally, a large-grained dense microstructure is formed, as seen in Figure 8(c), $t=11,282.38$ seconds. When combeite appears, it nucleates and grows in the cuspidine grains found close to the surface, causing the cuspidine to move to the interglobulite region, maintaining a dense microstructure. ${ }^{[41]}$ With the more complex devitrifying slag, in which several phases precipitate simultaneously, the grains nucleating and growing close to the surface adopt a feathery-like shape, as seen in Figure 9(c), $t=600.78$ seconds. These grains grow preferentially along one direction, resulting in poor packing in the directions perpendicular to this, leading to the formation of a skeletal structure of crystals separated by empty spaces or pores.

As temperatures increase, the spread of protruding crystals over a rigid adjacent surface are facilitated because the devitrified slags become fluid as the melting range is approached. Furthermore, melting starts at relatively low temperatures, as indicated by the endothermic peaks for melting of slags A and B, as shown in the thermoanalysis traces plotted in 


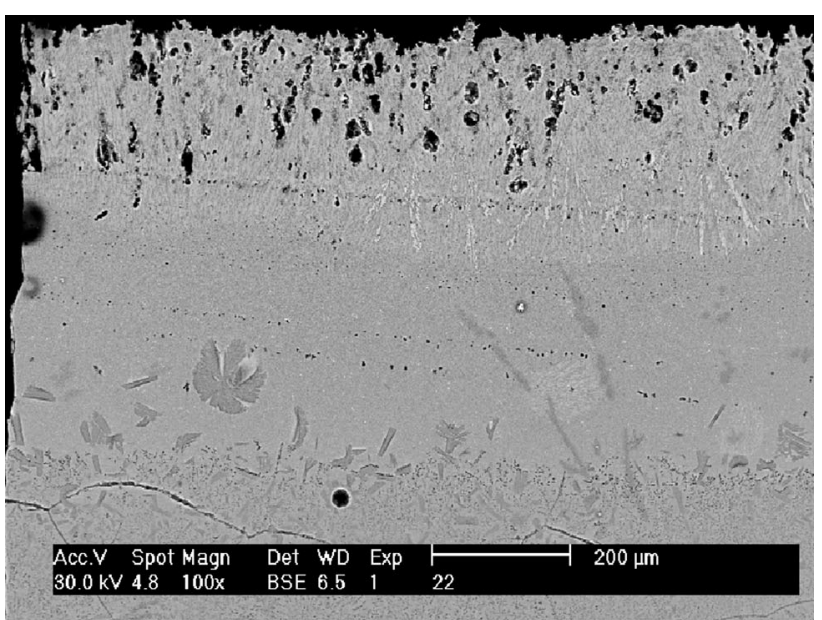

(b)

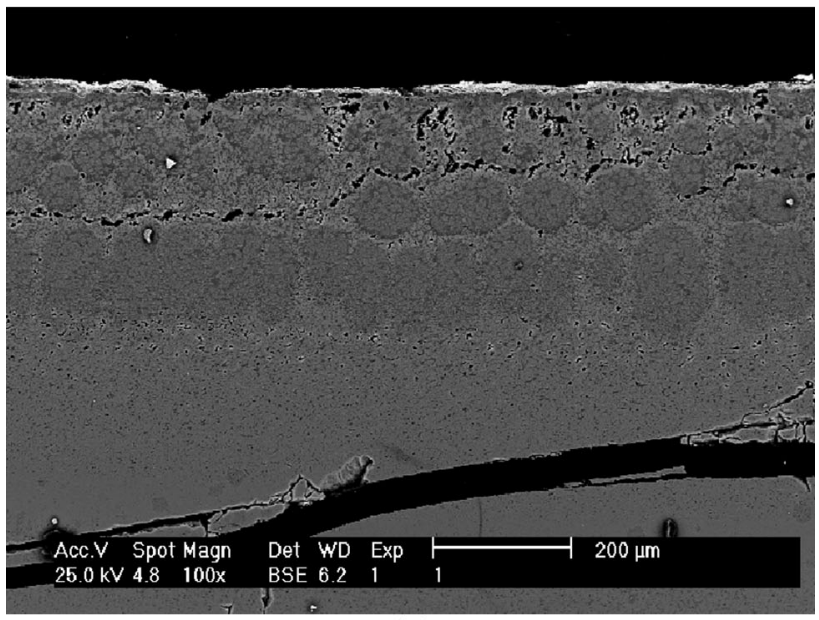

(a)

Fig. 13-Backscattered electron microscope images of regions close to the hot surface of slag disks treated during $10,800 \mathrm{~s}(3 \mathrm{~h})$ in the heat flux apparatus with $T_{\mathrm{c}}=1173 \mathrm{~K}\left(900{ }^{\circ} \mathrm{C}\right)$ : $(a)$ slag $\mathrm{A}, d_{\mathrm{t}}=$ $2.13 \mathrm{~mm}$; and $(b)$ slag $\mathrm{B}, d_{\mathrm{t}}=1.52 \mathrm{~mm}$.

Figures 12(a) and (b) for slags A and B, respectively. The molten phase starts appearing at $1235 \mathrm{~K}$ and $1186 \mathrm{~K}\left(962{ }^{\circ} \mathrm{C}\right.$ and $\left.913{ }^{\circ} \mathrm{C}\right)$ in slags $\mathrm{A}$ and $\mathrm{B}$, respectively. The exothermic peaks $P_{1}$ and $P_{2}$ in Figure 12(a) are linked to the formation of cuspidine and combeite, respectively, and the peak in Figure 12(b) is related to the formation of the five crystalline species reported in Figure 11(b). Observations at temperatures higher than $973 \mathrm{~K}\left(700{ }^{\circ} \mathrm{C}\right)$ are not reported with the arrangement described in Section II-C, used in the CLSM tests, because the specimens lose their shape, forming almost a hemisphere inside the u-shaped $\mathrm{Pt}$ foil. However, observations of slag disks recovered after tests carried out in the heat flux apparatus closely resemble the CLSM results described previously, clearly confirming the difference in pore size and degree of porosity formed during devitrification of slags A and B. Figures 13(a) and (b) show BSE images of regions of disks of slags A and $\mathrm{B}$, respectively, adjacent to the surface that was in contact with the crucible base. The microstructure of the devitrified disk $\mathrm{A}$ is much more compact than that of slag B, which shows many large pores in the immediate vicinity of the hot face. The ragged appearance of the border of specimen B suggests that the superficial pores were sealed during the test and that, during removal from the crucible, the surface broke, leaving a splintered edge. As the crucible temperature is higher, it becomes more difficult to recover the disk from the crucible, since when it cools, it acquires a slate-type structure that separates into layers. This behavior hindered the observation of the surface of specimens, and something similar could be responsible for causing uncertainty in the thickness of films recovered from operating molds.

\section{Estimated $R_{T}$ in CSP Molds}

In industrial trials covering a wide range of casting conditions, temperature measurements were carried out at the copper plates of an operating mold, and a two-dimensional steady-state analysis of these data, together with detailed considerations of the geometry of the mold, was used to establish appropriate boundary conditions for a two-dimensional, curvilinear-coordinate unsteady-state heat conduction model for predicting the solidification of thin slabs in CSP molds. ${ }^{[37,38]}$ These measurements and predictions were used in the present work to estimate the overall effective thermal resistance in CSP molds to compare it with the measurements carried out with the heat flux apparatus developed to investigate different experimental conditions.

The estimated mold temperature, $T_{\mathrm{m}}$, mold heat flux, $q_{\mathrm{m}}$, shell temperature, $T_{\mathrm{sh}}$, and overall effective thermal resistance between the mold and the shell, $R_{\mathrm{T}}$, are shown in Figures 14(a) through (d), respectively, for operation with mold powder A (solid line) and B (dash line); the distributions are along the center of the broad face of the mold and correspond with a casting velocity of $4.21 \mathrm{~m} / \mathrm{s}$. Figure 14(d) shows that the thermal resistance is lower in the upper part of the mold, where the change in the cross section of the funnel is more important. Then there is a transition in thermal resistance from 0.4 to $0.6 \mathrm{~m}$ from the meniscus, until reaching the largest values in the straight section of the mold. From the plant estimations, it is calculated that the thermal resistance of mold slag B is, on average (from the meniscus to the mold exit), 37 pct higher than that for mold slag A. In the laboratory, the measured percentage difference (for the different disk thicknesses and temperatures investigated) is 33 pct, as indicated in Section IV-B. Furthermore, comparing the overall thermal resistances in the mold, as shown in Figure 14(d), with the values of the extrapolated lines exhibited in Figures 6(a) and (b), it could be expected that the slag film in the mold must be around 0.1 to $0.25 \mathrm{~mm}$, which is in line with the film thicknesses reported in the literature. ${ }^{[28-30]}$ 


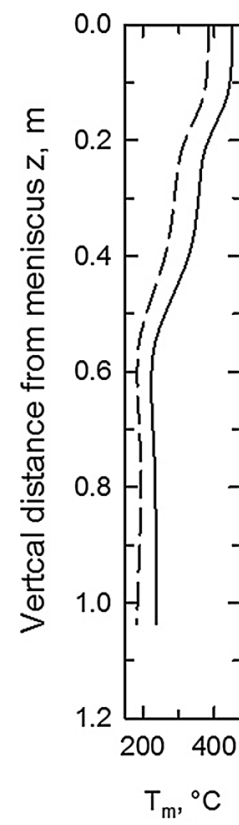

(a)

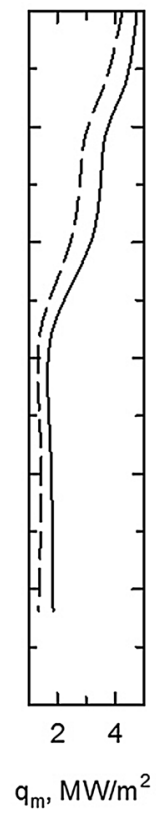

(b)

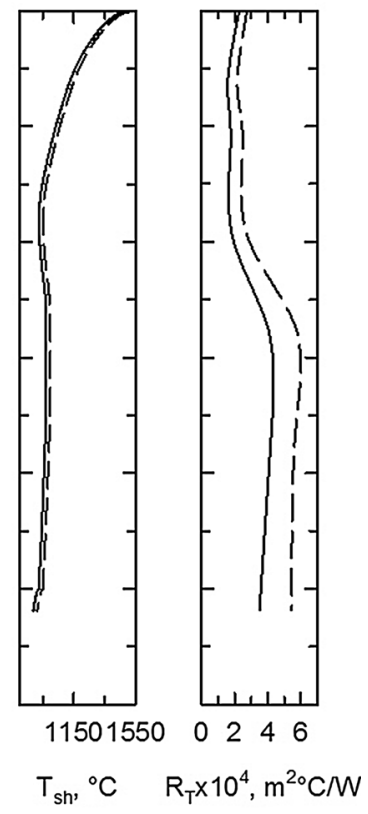

(d)
Fig. 14-Model estimated profiles of $(a)$ mold surface temperature; (b) mold heat flux; $(c)$ shell surface temperature; and $(d)$ total effective mold-shell thermal resistance, along the length of the mold from the meniscus. Solid line, mold powder A; and dash line, mold powder B.

\section{SUMMARY AND CONCLUSIONS}

This study investigates experimentally the total effective thermal resistance, $R_{\mathrm{T}}$, between a hot Inconel surface and a cold $\mathrm{Cu}$ surface separated by an initially glassy slag disk, made from powders for casting low, A, and medium, $\mathrm{B}$, carbon steels. In the tests, an initially glassy disk is sandwiched for 3 hours while the temperature of the Inconel away from the disk face is maintained steady at a value between $973 \mathrm{~K}$ and $1423 \mathrm{~K}\left(700{ }^{\circ} \mathrm{C}\right.$ and $\left.1150{ }^{\circ} \mathrm{C}\right)$, i.e., below the liquidus temperature of the slags studied. The disks used have a thickness between $\sim 0.7$ and $3.2 \mathrm{~mm}$, and their faces are mirror polished. Furthermore, for investigating flux-mold gap formation, detailed observations by CLSM are done of the motion that the surface of a glassy slag parallelepiped experiences relative to a stationary surface, while devitrifying at different temperatures. Also, plant information is analyzed to evaluate $R_{\mathrm{T}}$ in actual CSP mold operation and to compare it with values measured in the laboratory.

The heat flux measurements reveal that the interfacial thermal resistances for mold slags $\mathrm{A}$ and $\mathrm{B}$ are not significantly different and that the difference in the thermal characteristics that they exhibit under devitrification arises from distinctness in the characteristics of the films. Since for the temperatures and times investigated both slags were fully crystallized and since their optical properties are expected to be similar, their distinction must stem from differences in porosity. Inspection of disks after treatment supports this factor as the cause of the disparity, and CLSM observations confirm the much greater porosity that develops in the mold powder slag B compared to A. In case of slag A, the crystalline grains growing at or near the surface pack closely together, leaving only few and small empty spaces. In slag B, the crystalline grains pack loosely and many and large empty spaces arise in the surface and inside the body. The CLSM observations also reveal that during devitrification the surfaces of the slag move outward not inward, i.e., expand not shrink - contrary to what is widely claimed. This behavior would favor contact of the slag with the mold for both kinds of powders. To the best of our knowledge, this is the first time direct evidence is presented about the phenomena occurring at the interface between a devitrifying slag and a wall.

In the laboratory, the total effective thermal resistance of slag B resulted in average (for the different disk thicknesses and temperatures investigated) 33 pct larger than that of slag A. This value compares well with the difference of 37 pct estimated for the same powders from plant data obtained in a CSP mold. Additionally, comparison of laboratory and plant values of the thermal resistance $R_{\mathrm{T}}$ suggests that the slag film thickness in the mold must be around 0.1 to $0.25 \mathrm{~mm}$.

\section{ACKNOWLEDGMENTS}

The authors thank Miss Adriana A. García S. and Mr. Roberto Soto V. for providing the results presented in Figure 12. We are grateful also to the National Council of Science and Technology of México (CONACYT) for the financial support received through Grant No. 241103. JMGdlC and TMFF express their gratitude to CONACYT for the respective Ph.D. and M.Sc. scholarship grants obtained.

\section{NOMENCLATURE}

$d_{\mathrm{t}} \quad$ Disk thickness, $\mathrm{m}$

$d, d_{\mathrm{m}}, d_{\mathrm{s}} \quad$ Distance between thermocouples;

distance between thermocouple 1 and $\mathrm{m}$ surface; distance between thermocouple 3 and s surface $(\mathrm{m})$

$k_{\mathrm{Cu}}, k_{\mathrm{eff}}, k_{\mathrm{In}} \quad$ Copper; effective; Inconel conductivity $(\mathrm{W} / \mathrm{m} \mathrm{K})$

$P$

$q_{\mathrm{eff}}, q_{\mathrm{m}}$

$R_{\mathrm{T}}, R_{\text {int }}$

Peak in thermoanalysis trace

$T$

$T_{\mathrm{i}}, T_{\mathrm{m}}$ Effective; mold heat flux $\left(\mathrm{W} / \mathrm{m}^{2}\right)$ Overall effective thermal resistance; interfacial thermal resistance $\left(\mathrm{m}^{2} \mathrm{~K} / \mathrm{W}\right)$ Temperature $\left[\mathrm{K}\left({ }^{\circ} \mathrm{C}\right)\right]$

Onset temperature of devitrification phases; temperature at peak maximum of devitrification peaks

\section{SUBSCRIPTS}

c Control

$\mathrm{m} \quad$ Surface of $\mathrm{Cu}$ fingertip or mold surface

s, sh Surface of crucible base; strand surface

1, 2, 3, 4 Subscripts identifying thermocouples; peak number in DSC devitrification trace 


\section{REFERENCES}

1. J.K. Brimacombe and K. Sorimachi: Metall. Trans. B, 1977, vol. 8B, pp. 489-505.

2. A. Grill, K. Sorimachi, and J.K. Brimacombe: Metall. Trans. B, 1976, vol. 7B, pp. 177-89.

3. B.G. Thomas, J. Bentsman, B. Petrus, X. Zhou, K. Zheng, S. Vapalahti, H. Li, and A.H. Castillejos: Proc. 2009 NSF Engineering Research and Innovation Conf., Honolulu, HI, 2009, Grant No. DMI-0500453.

4. W.H. Emling: in The Making, Shaping and Treating of Steel, A.W. Cramb, ed., The AISE Steel Foundation, Pittsburgh, PA, 2003, pp. $1-34$.

5. R.J. O'Malley and J. Neal: Proc. METEC Congr. 99, Dusseldorf, 1999, vol. 1, pp. 188-95.

6. W. Yan, W.Q. Chen, C. Lippold, and H.G. Zheng: La Metallurgia Italiana, 2013, pp. 35-42.

7. D.T. Stone and B.G. Thomas: Can. Metall. Q., 1999, vol. 38, pp. 363-75.

8. K. Watanabe, M. Suzuki, K. Murakami, H. Kondo, and T. Shiomi: Steelmaking Conf. Proc., 1996, vol. 79, pp. 265-68.

9. F. Ma, Y. Liu, W. Wang, and H. Zhang: Metall. Mater. Trans. B, 2015, vol. 46B, pp. 1902-11.

10. K. Mills: in Treatise of Process Metallurgy, vol. 3, Industrial Processes, Part A, S. Seetharaman, ed., Elsevier Ltd., Oxford, United Kingdom, 2014, pp. 448-49.

11. R. Saraswat, D.M. Maijer, P.E. Lee, and K.C. Mills: ISIJ Int., 2007, vol. 47, pp. 95-104.

12. K. Tsutsumi, T. Nagasaka, and M. Hino: ISIJ Int., 1999, vol. 39, pp. $1150-59$.

13. J.W. Cho and H. Shibata: J. Non-Crystalline Solids, 2001, vol. 282, pp. 110-17.

14. S. Ohmiya, K.H. Tacke, and K. Schwerdtfeger: Ironmaking and Steelmaking, 1983, vol. 10, pp. 24-30.

15. A. Yamauchi, K. Sorimachi, T. Sakuraya, and T. Fujii: ISIJ Int., 1993, vol. 33, pp. 140-47.

16. J. Cho, H. Shibata, T. Emi, and M. Suzuki: ISIJ Int., 1998, vol. 38 , pp. 440-46.

17. S. Mineta, T. Kajitani, and H. Yamamura: AISTech 2010 Conf. Proc., 2010, vol. 2, pp. 71-80

18. A.C. Mikrovas, S.A. Argyropoulos, and I.D. Sommerville: Ironmaking and Steelmaking, 1991, vol. 18, pp. 169-81.

19. Y. Liu, W. Wang, F. Ma, and H. Zhang: Metall. Mater. Trans. B, 2015, vol. 46B, pp. 1419-30.
20. H. Zhang, W. Wang, F. Ma, and L. Zhou: Metall. Mater. Trans. $B, 2015$, vol. 46B, pp. 2361-73.

21. J.-Y. Park, E.-Y. Ko, J. Choi, and I. Sohn: Metall. Mater. Int., 2014, vol. 20, pp. 1103-14

22. J. Cho, H. Shibata, T. Emi, and M. Suzuki: ISIJ Int., 1998, vol. 38, pp. 268-75.

23. W. Wang and A.W. Cramb: ISIJ Int., 2005, vol. 45, pp. 1864-70.

24. K. Gu, W. Wang, J. Wei, H. Matsuura, F. Tsukihashi, I. Sohn, and D.J. Min: Metall. Mater. Trans. B, 2012, vol. 43B, pp. 13931404.

25. C. Xu, W. Wang, L. Zhou, S. Xie, and C. Zhang: Metall. Mater. Trans. B, 2015, vol. 46B, pp. 882-92.

26. H. Nakada, M. Susa, Y. Seko, M. Hayashi, and K. Nagata: ISIJ Int., 2008, vol. 48, pp. 446-53.

27. F. Neumann, J. Neal, M.A. Pedroza, and A.H. Castillejos E: Steelmaking Conf. Proc., 1996, vol. 79, pp. 249-58.

28. J.A. Kromhout, E.R. Dekker, M. Kawamoto, and R. Boom: Ironmaking and Steelmaking, 2013, vol. 40, pp. 206-15.

29. J.A. Kromhout, C. Liebske, S. Melzer, A.A. Kamperman, and R. Boom: Ironmaking and Steelmaking, 2009, vol. 36, pp. 291-99.

30. S.Y. Kim, Y.S. Choi, J.Y. Hwang, and S.H. Lee: AISTech 2015 Conf. Proc., 2015, vol. 2, pp. 2507-22.

31. M. Hanao and M. Kawamoto: ISIJ Int., 2008, vol. 48, pp. 180-85.

32. P. Duvvuri, B. Petrus, and B.G. Thomas: AISTech 2014 Conf. Proc., 2014, vol. 2, pp. 1-13.

33. R. Bommaraju: 74th Steelmaking Conf. Proc., 1991, pp. 131-46.

34. J.M. González de la C.: Ph.D. Progress Report, CINVESTAV-Unidad Saltillo, Coahuila, Mexico, 2015.

35. R.W. Powell, C.Y. Ho, and P.E. Liley: "Thermal Conductivity of Selected Materials," NSRDS-NBS 8 Report, http://www.nist.gov/ data/nsrds/NSRDS-NBS-8.pdf.

36. Inconel Alloy 601, Special Metals, http://www.specialmetals.com/ assets/documents/alloys/inconel/inconel-alloy-601.pdf.

37. J.E. Camporredondo S, A.H. Castillejos E, E.P. Gutiérrez, and M.A. Herrera G: Metall. Mater. Trans. B, 2004, vol. 35B, pp. 541-60.

38. J.J. Montes R, A.H. Castillejos E, E.P. Gutiérrez M, and M.A. Herrera G: Can. Metall. Q., 2008, vol. 47, pp. 187-204.

39. Y.G. Maldonado, C. Barraza de la P, S. Rodríguez A, A.H. Castillejos E, and B.G. Thomas: Metall. Mater. Trans. B, 2015, vol. 46B, pp. 286-303.

40. Y.G. Maldonado and A. Humberto Castillejos E: Mater. Design, 2015, vol. 83, pp. 728-35.

41. Tania M. Flores F.: CINVESTAV-Unidad Saltillo, Coahuila, Mexico, unpublished research in progress, 2016. 